\title{
A Novel Approach Based on Kano Model, Interval 2-Tuple Linguistic Representation Model, and Prospect Theory for Apperceiving Key Customer Requirements
}

\author{
Aijun Liu $\mathbb{D}^{1},{ }^{1,2}$ Qiuyun Zhu $\mathbb{D}^{1},{ }^{1}$ Haiyang Liu $\mathbb{D}^{1},{ }^{1}$ Hui Lu ${ }^{(D)},{ }^{3}$ and Sang-Bing Tsai ${ }^{4}{ }^{4}$ \\ ${ }^{1}$ School of Economics and Management, Xidian University, No. 2 Taibai South Street, Xian 710071, China \\ ${ }^{2}$ State Key Laboratory for Manufacturing Systems Engineering, Xi'an Jiaotong University, Xian 710049, China \\ ${ }^{3}$ Tianhua College, Shanghai Normal University, Shanghai 201815, China \\ ${ }^{4}$ Zhongshan Institute, University of Electronic Science and Technology of China, Zhongshan 528402, China
}

Correspondence should be addressed to Hui Lu; janetluck@126.com and Sang-Bing Tsai; sangbing@hotmail.com

Received 18 December 2017; Accepted 3 April 2018; Published 18 July 2018

Academic Editor: Francesco Riganti-Fulginei

Copyright (C) 2018 Aijun Liu et al. This is an open access article distributed under the Creative Commons Attribution License, which permits unrestricted use, distribution, and reproduction in any medium, provided the original work is properly cited.

\begin{abstract}
The precisely perception of key customer requirements (CRs) is critically important for customer collaborative product innovation (CCPI) design. A novel approach is proposed based on the Kano model, interval 2-tuple linguistic representation model, and prospect theory. First of all, a Kano model is constructed to preliminarily screen the relatively important product function attributes. For the uncertain and vague information of CRs, an interval 2-tuple linguistic representation model is proposed to determine the weight of CRs. Then, the comprehensive prospects value is utilized for sorting the innovative programs based on the prospect theory. Finally, a numerical example is given to verify the scientific and validity of the proposed method.
\end{abstract}

\section{Introduction}

With the increasingly fierce market competition, as well as more and more personalized and diversified CRs, it is very critical for the modern manufacturing enterprises to grasp customers' key requirements in a relatively short time because of the complexity of decision-making problems and the fuzziness of decision-making environments (Liu and Wang [1]). What is more, integrating the CRs into the product design is very important for successful product development in CCPI, which can effectively enhance the communication between enterprises and customers and then improve the performance of enterprises. For example, Franke and Von Hippel [2] proposed a study to satisfy heterogeneous customer requirements via innovation toolkits, and the case of Apache security software proved that collaborative innovation can bring rich profits to the company. Besides, Lilien et al. [3] compared and analyzed the CCPI process of $3 \mathrm{M}$ in the United States and illustrated the clear benefits of customer innovation with actual sales data. Nowadays, this method has been widely used in product design (Song et al. [4]; Dahl et al. [5]). It is well known that the key CRs is the core of CCPI; however, due to the expression of key CRs it is too subjective and vagueness to be accurately obtained. Based on this, we integrate Kano model, the interval 2-tuple linguistic representation model, and prospect theory to determine the key customer requirements.

Over the past decade, the way of identifying key customer requirements including qualitative and quantitative methods was developed. About qualitative method, Chen et al. [6] proposed an ontology learning CRs representation system, the system which preprocessed customer statements by language processing tools. Wang and Tseng [7]; Wang and Tseng [8] put forward the concept of customer demand bias and employed probability analysis methods to analyze CRs. Liu et al. [9] proposed a system management approach for demand management in industrial design. Violante et al. [10] developed a user-centric approach that can meet the specific requirements of the company and help organizations effectively identify selection tools. Sheng et al. [11] took the product service system as the research object, constructed the quality house, and determined the attribute weight of the 


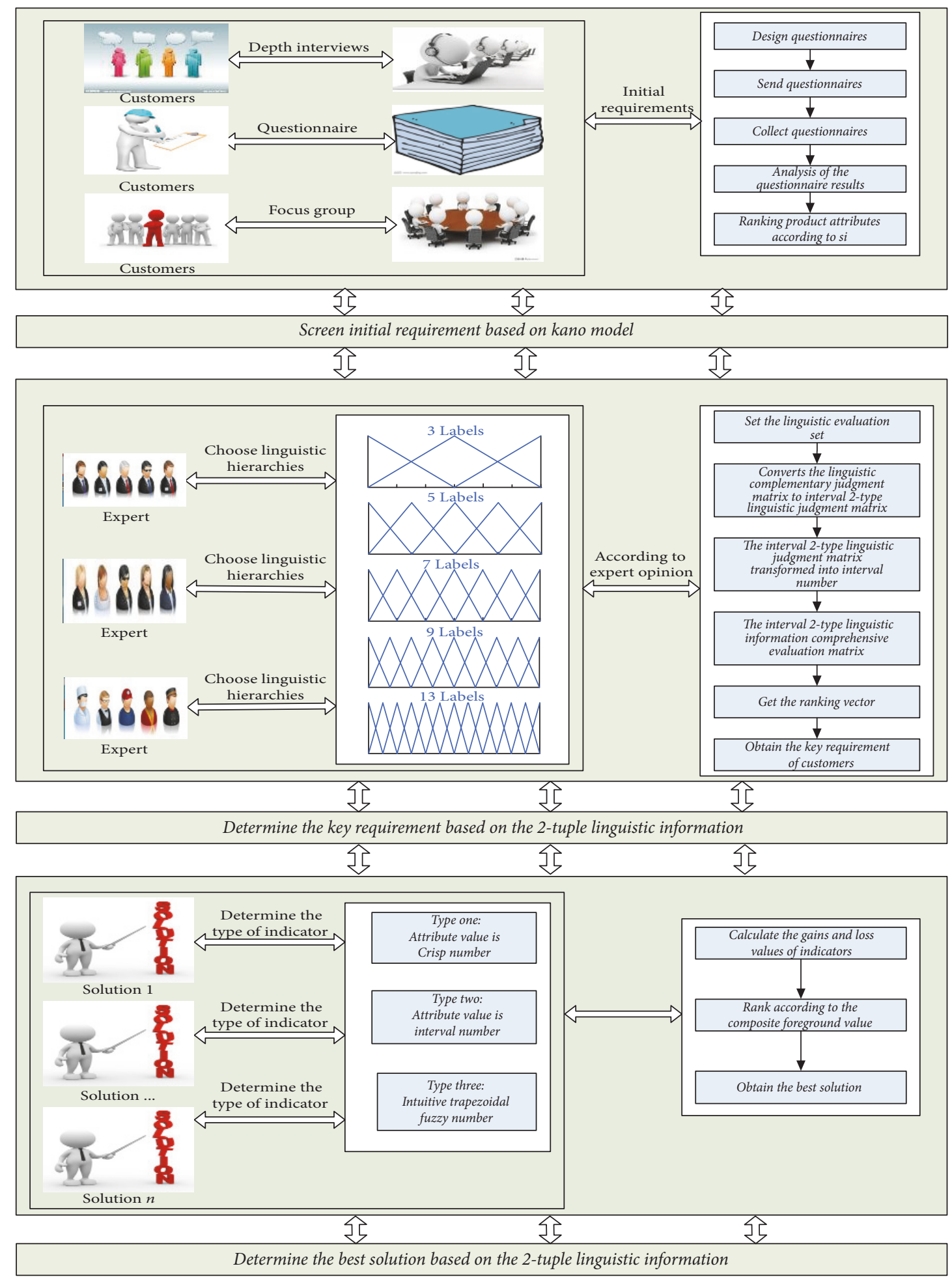

FIGURE 1: The method we proposed.

product and service. Carulli et al. [12] proposed a method for capturing CRs based on virtual reality technology, which was commonly used in the early stages of product design to deduce CRs and reduce overall cost. In order to solve the problem of inaccurate customer demand, Kwong and Bai [13] introduced the fuzzy number on the basis of traditional AHP and proposed the fuzzy AHP to determine the importance of customer demand. In the process of product collaborate design, Halimahtun [14] used a system framework approach to conceptualize the current and future customer demand for 
automotive electronics. The qualitative method is simple and easy to operate, but its subjectivity is too strong to reflect the essential differences between items; the results obtained are more abstract. The application effect of qualitative method is unconvincing.

As for quantitative method, Li et al. [15] combined minimum deviation method, the Balanced Scorecard, the analytic hierarchy process (AHP), the proportional method, and so on and proposed a system operation method that can make better use of product competition and preference information. Due to the ambiguity and uncertainty of the customers' requirements, Wang and Tseng [16] established a probabilitybased Bayesian classifier by using existing customer selection data, the classifier classified CRs based on the flexibility of customer demand. Finally, the case proved that this method had obvious advantages in customer demand classification. Aguwa et al. [17] developed a new approach to measure customer satisfaction by considering quantitative factors such as quantitative data, design parameters, drawing output, and decision-making templates for means of measurement. This method can reduce errors and shorten the engineering development time. Liu et al. [18] used language intuitionistic fuzzy number to describe the decision maker's language information. Then comparative analysis method is used to prove the validity of the proposed method. Nahm et al. [19] proposed two methods of customer preference and customer satisfaction assessment; the former provided a way to capture incomplete and uncertain information about the customer and the latter built a customer satisfaction model based on competitive benchmarking; finally, the effectiveness of the proposed method was proved by a door design example. Wu et al. [20] integrated the gray relational theory into the Quality Function Deployment (QFD), this method, taking the uncertainty and advancement of CRs into account, was utilized to analyze dynamic CRs. Liu et al. [21] presented an approach to address the dependent attribute problem leading to a function form with design attributes as independent variables and proved the potential to optimize the design specification. Takai and Ishii [22] analyzed and compared two methods for identifying representative needs affinity diagram (AD) and subjective clustering (SC); the CRs analysis of the next generation particle accelerator was used to demonstrate the scientific nature of the proposed method. The establishment of the key customer requirements is crucial to CCPI, and the weight of key customer requirements is the core of innovation program selection. The fuzzy language information in fuzzy decision is often expressed by fuzzy number (Liu et al. [23]; Liu and Chen [24]), language scale, and interval 2-tuple linguistic representation model. All research results suggest that constructing interval 2tuple linguistic representation model is an effective method to donate the information of decision-makers. Based on 2tuples and intervals, Dong et al. [25] proposed a linguistic computational model, summarized the numerical scale approach, and conducted comparative analysis to justify the effectiveness of the interval version of the 2-tuple fuzzy linguistic representation model. Herrera and Martinez [26]; Herrera and Martinez [27] pointed out that the binary semantic representation model was widely used to solve the multiattribute decision-making problem based on language evaluation information; it had high expression accuracy. Li et al. [28] and Li et al. [29] proposed the personalized individual semantics in 2-tuple linguistic model. Dong et al. [30] propose a connection between the linguistic hierarchy model and the numerical scale model. They also prove the equivalence of the linguistic computational models by equating the model. Chen et al. [31] analyzed three types of fusion approaches to manage the fusion process in group decision-making with heterogeneous preference structures and reviewed the different transformation functions among utility values, preference orderings, numerical preference relations, and multigranular linguistic preference relation. Dong et al. [32] considered four formats of information, i.e., real numbers, intervals, linguistic variables, and triangular fuzzy numbers and proposed framework to solve complex and dynamic multiple attribute group decision-making problems. As can be seen from the above literature, interval 2-tuple linguistic can handle the information of decisionmakers well in a fuzzy environment. Based on this, we use the interval 2-tuple linguistic representation model to collect and express the information of decision-makers and then determine the key customer requirements in CCPI. In the process of CCPI design, due to the constraints of resources and costs, the degree of implementation of key customer requirements can not always reach the maximum. Therefore, it is necessary to choose a better innovative scheme. The selection of innovative scheme is a process of MCMD. Liu [33] combined the power average operator with Heronian mean operator and extended them to process interval-valued intuitionistic fuzzy information and presented fuzzy multiple attribute group decision-making. Liu and Li [34] extended the power Bonferroni mean operator (PBM) to process interval-valued intuitionistic fuzzy numbers (IVIFNs) and applied them to solve the MAGDM problems. Lahdelma and Salminen [35] proposed a new decision-making method based on the combination of the prospect theory and the Stochastic Multicriteria Acceptability Analysis (SMAA) for stochastic multiattribute decision-making with incomplete preference information. Based on the interaction operational laws of intuitionistic fuzzy sets (IFSs) Liu et al. [36] extended the PBM operator and the PGBM operator, and then they proposed a novel MAGDM method. Grabisch et al. [37]; Grabisch et al. [38] presented both a constructive view and a descriptive view on alternatives evaluation in the process of multicriteria decision analysis. The descriptive approach was concerned with characterizations of models of preference, whereas the constructive approach aimed at building preferences by questioning the decision maker. The result of quantitative methods is more intuitive, concise, accurate, and effective than qualitative method. However, its operation often has some difficulties; especially some related factors are difficult to quantify, affecting the accuracy of quantification.

Based on this, we combine qualitative and quantitative methods to determine the key requirements of customers. This paper integrates the Kano model, the interval 2-tuple linguistic representation model, and the prospect theory; Kano model as a qualitative method is proposed to identify the initial requirements of customers. It is simple and easy to 
operate. Because of the difference of customers' knowledge structure, experience, and other objective or subjective factors, some CRs expression may be uncertain linguistic preference. The interval 2-tuple linguistic representation model and the prospect theory are proposed to deal with the uncertainty. The interval 2-tuple linguistic representation model could be more accurate in terms of vague linguistic preference and less information loss in fuzzy information processing. Therefore, it is appropriate to select the 2-tuple linguistic representation model to illustrate fuzzy linguistic preference in the process of determining CRs' weight. Because CRs are diversity, enterprises can not meet completely; based on this, we used prospect theory to evaluate the products' comprehensive prospects value in order to achieve the maximum level of customer satisfaction.

The remainder of this paper is organized in the following manner: Section 2 is CRs analysis based on the Kano model. Section 3 is the innovative product program selection based on the prospect theory. In Section 4, an empirical example is provided to demonstrate the applicability of the proposed method. Comparative analysis is given in Section 5. Finally, some conclusions and future research directions are summarized in Section 6.

The article frame work we proposed is shown in Figure 1.

\section{Analysis of CRs Based on Kano Model}

The customer can not specify the desired product attributes accurately in a real buying scenario. It is unscientific to determine the true requirements of customers simply by a simple questionnaire. Therefore, systematic methodological tools to clarify the real requirements of customer are necessary. Kano model as a valid method is proposed to identify the key CRs.

2.1. Identification of the Initial CRs of a Product. The Kano model, as a relative accuracy expression of CRs, is used to realize CRs and their effect on customer satisfaction (CS). It can classify different CRs and find attractive requirements of products. Promoting enterprises produce more popular products which can stand out from similar products.

According to the size of the CRs impact on CS, Kano model divides CRs into five types requirements, which are must-be requirements, one-dimensional requirements, attractive requirements, indifference requirements, and reverse requirements, as shown in Figure 2.

The horizontal axis is the satisfaction degree of one specific CR and the vertical axis means the satisfaction degree of CS.

Must-Be Requirements (M). Customers will accept if this attribute is provided; otherwise they will feel extremely dissatisfied.

One-Dimensional Requirements (O). CS is a linear function of the satisfaction degree of a certainly CR. High satisfaction degree leads to high satisfaction and low satisfaction degree leads to low satisfaction
Attractive Requirements (A). Customers will be very satisfied if the requirement is met; if the requirement is not met they will accept the product with satisfaction also.

Indifference Requirements (I). Regardless of the fact that requirement is satisfied or not, CS will not be impacted.

Reverse Requirements (R). Customers do not want the attribute in the product, and absence of this attribute increases the degree of CS.

2.2. Determine the Type of CRs Based on Kano Model. Establishing the Kano model of CRs is vital for a product design, and the common tools for determining the initial CRs are Kano questionnaire, Kano assessment table, and Kano survey results table. The main steps are as follows.

Step 1. Design the Kano questionnaire. The Kano model provides a format for obtaining customer answers on each potential product attribute. The Kano questionnaire is shown in Table 1.

From Table 1, we can know that customers have to select one of the states out of Dislike, Could understand, Neutral, Of course, and Like from the product meet the requirement side, if the requirement is met in the product. Customers also have to select one of the states from the products do not meet the requirement side.

Step 2. The Kano questionnaire was issued. All possible combinations of customer answers and the corresponding type of product attribute are summarized in Table 2.

As seen from Table 2, besides the five types of requirement have involved, there is one more type of requirement called Q, where $Q$ represents a questionable answer and the answer is invalid. It occurs when customers select like or dislike from both functional and dysfunctional sides.

Step 3. By combining the two answers in the Kano evaluation table (Table 2), the product criterion can be identified as attractive, must-be, one-dimensional, indifference, or reversal; the results are shown in Table 3.

In order to maximize CS, we should consider the following points (Sharif Ullah and Tamaki [39]):

(i) Keep must-be attributes

(ii) As far as possible to meet the one-dimensional attributes and charm attributes

(iii) Avoid indifferent attributes as many as possible

(iv) Avoid reverse attributes

Step 4. Calculate satisfaction coefficient and dissatisfaction coefficient.

The quantitative analysis of Kano's model begins with calculating CS and DS (Ji et al. (2014)). Due to the diversification of CRs, CS and DS values only indicate the average 


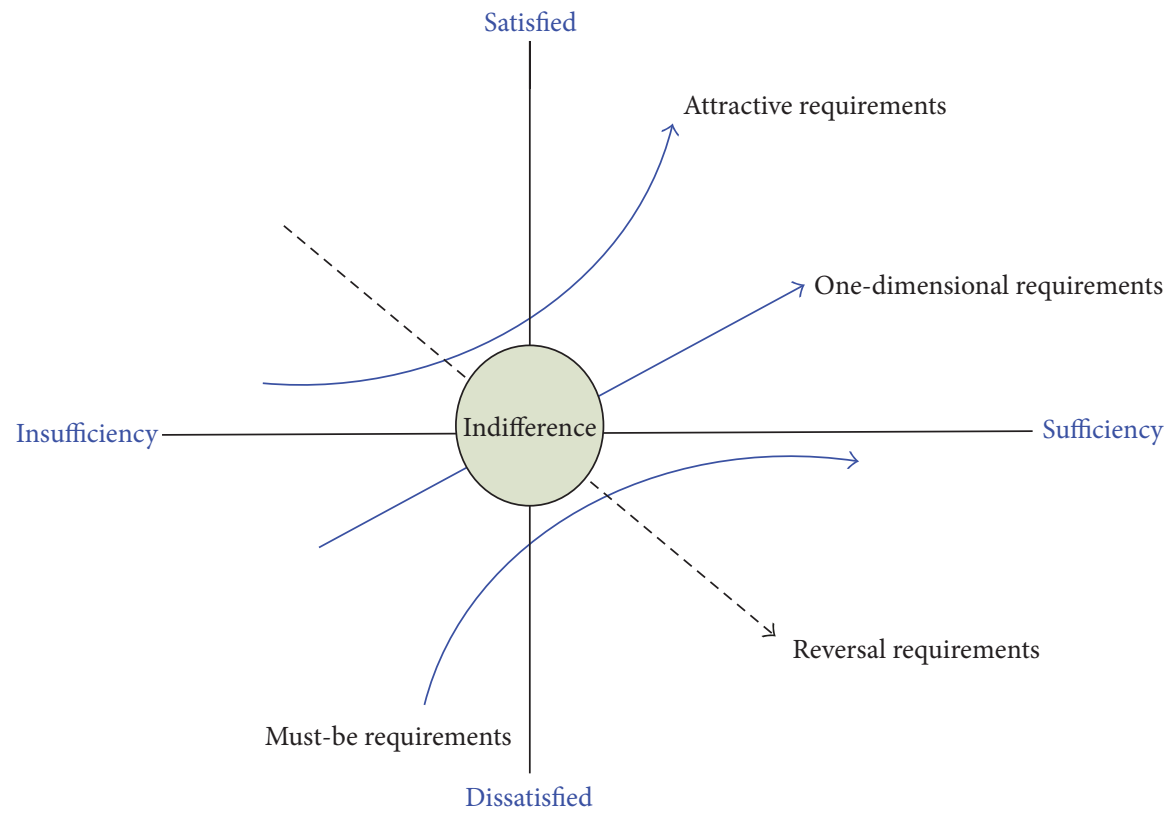

Figure 2: Kano model of customer satisfaction.

TABLE 1: Kano questionnaire table.

\begin{tabular}{|c|c|c|c|c|c|c|}
\hline Requirement & Problem & Dislike & Could understand & Neutral & Of course & Like \\
\hline \multirow{2}{*}{$R_{i}$} & Products meet the requirement (select one) & & $\sqrt{ }$ & & & \\
\hline & Products do not meet the requirement (select one) & & & $\sqrt{ }$ & & \\
\hline
\end{tabular}

TABLE 2: Kano evaluation table.

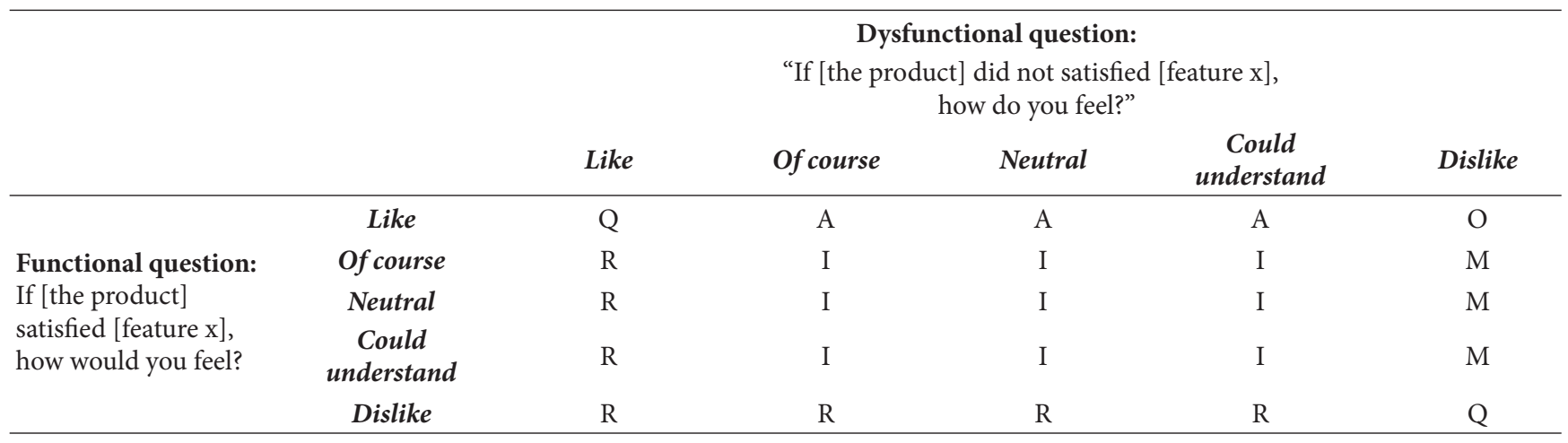

TABLE 3: Classification table of requirements.

\begin{tabular}{lccccccc}
\hline Requirements & $\mathrm{A}$ & $\mathrm{O}$ & $\mathrm{M}$ & $\mathrm{I}$ & $\mathrm{R}$ & Total number of questionnaires & Kano category \\
\hline$R_{1}$ & 20 & 25 & 15 & 22 & 18 & 100 & $\mathrm{O}$ \\
$R_{2}$ & 15 & 25 & 15 & 15 & 30 & 100 & $\mathrm{R}$ \\
$\ldots$ & $\ldots$ & $\ldots$ & $\ldots$ & $\ldots$ & $\ldots$ & $\ldots$ & \\
\hline
\end{tabular}

TABLE 4: $C S_{i}-C D S_{i}$ relationship functions.

\begin{tabular}{|c|c|c|c|c|}
\hline Kano category & $\mathrm{A}$ & $\mathrm{B}$ & $f\left(y_{i}\right)$ & $s_{i}=A f\left(y_{i}\right)+B$ \\
\hline A & $\frac{C S_{i}-D S_{i}}{e-1}$ & $-\frac{C S_{i}-e D S_{i}}{e-1}$ & $e^{y_{i}}$ & $s_{i}=\frac{C S_{i}-D S_{i}}{e-1} e^{y i}-\frac{C S_{i}-e D S_{i}}{e-1}$ \\
\hline $\begin{array}{l}\mathrm{O} \\
\mathrm{M}\end{array}$ & $\begin{array}{c}C S_{i}-D S_{i} \\
e\left(C S_{i}-D S_{i}\right) \\
e-1\end{array}$ & $\begin{array}{c}D S_{i} \\
\frac{e C S_{i}-D S_{i}}{e-1}\end{array}$ & $\begin{array}{c}y_{i} \\
-e^{y_{i}}\end{array}$ & $\begin{array}{c}s_{i}=\left(C S_{i}-D S_{i}\right) y i+D S_{i} \\
s_{i}=-\frac{e\left(C S_{i}-D S_{i}\right)}{e-1} e^{y_{i}}+\frac{e C S_{i}-D S_{i}}{e-1}\end{array}$ \\
\hline
\end{tabular}




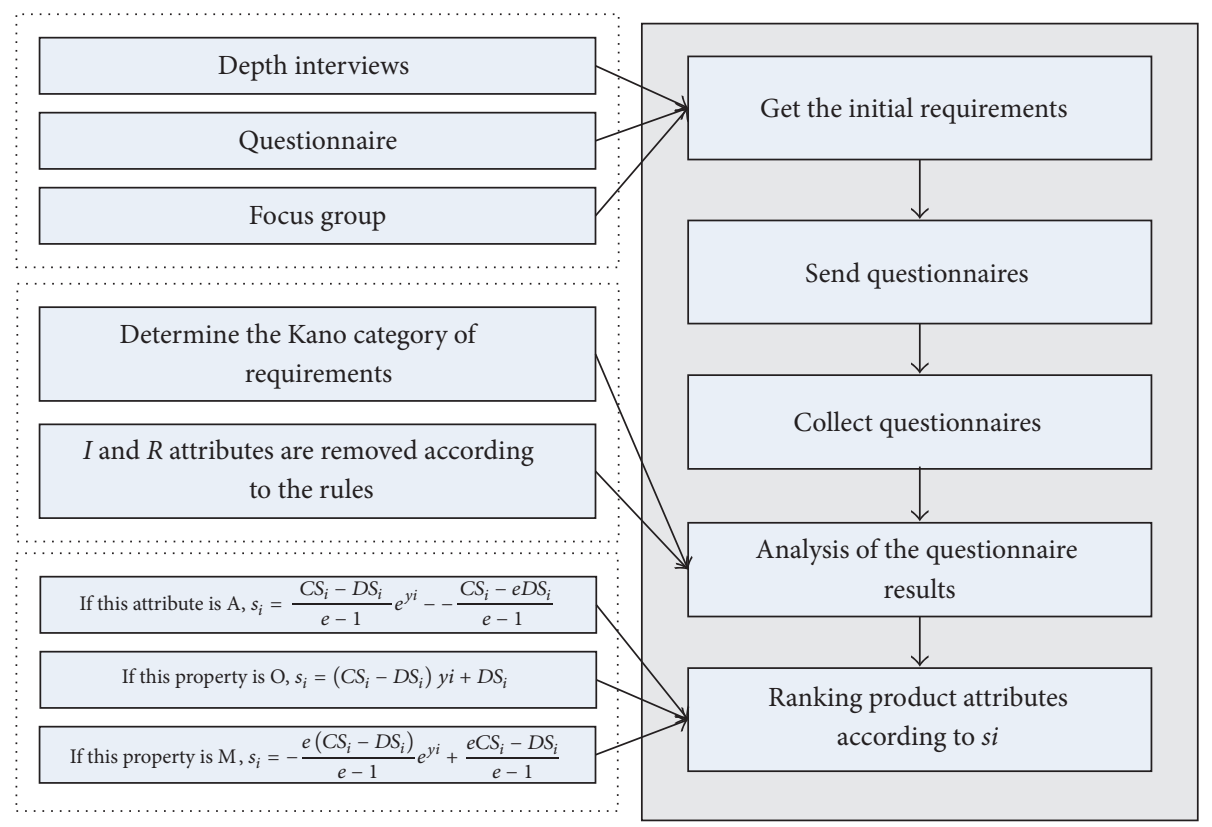

Figure 3: The flow chart based on Kano model.

contribution of one CR to CS, which can be represented by the number of customers who are satisfied or dissatisfied with a certain CR. From Table 3, we can sum up the number of attractive attributes $N_{A}$, one-dimensional attributes $N_{O}$, must-be attributes $N_{M}$, and indifferent attributes $N_{I}$, and then we can get the value of $C S_{i}$ and $C D S_{i}$ by formulations (1) and (2):

$$
\begin{gathered}
C S_{i}=\frac{N_{A}+N_{O}}{N_{A}+N_{O}+N_{M}+N_{I}} \\
C D S_{i}=-\frac{N_{M}+N_{O}}{N_{A}+N_{O}+N_{M}+N_{I}}
\end{gathered}
$$

Step 5. According to Table $4, C S_{i}-C D S_{i}$ relationship functions could be obtained (Ji et al. [40]).

Step 6. A rank for CRs is made according to the value of $s_{i}$.

The flow chart based on Kano model is shown in Figure 3.

2.3. Weight Determination of CRs. In product design, it is very difficult for product design decision-makers due to the vagueness and uncertainty of the CRs. In order to solve this difficult, Lin et al. [41] proposed the concept of interval 2tuple linguistic and investigated the possibility of interval 2tuples linguistic.

It is used for representing the linguistic assessment information by means of a 2-tuple $\left(s_{i}, \alpha_{i}\right)$, where $s_{i}$ is a linguistic label from predefined linguistic term set $S$ and $\alpha_{i}$ is the value of symbolic translation (Dong et al. [42]; Wei [43]; Zhang [44]; Zhang [45]; Gangurde and Akarte [46]; Liu and Chen [47]; Qin and Liu [48]; Wang et al. [49]). See Figure 4.

Definition 1. Let $S=\left\{s_{0}, s_{1}, \ldots, s_{g}\right\}$ be a linguistic term set, and $\alpha$ represents the deviation between the linguistic information and the closest linguistic phrase in the initial linguistic evaluation set $S$, the real number. $(\beta \in[0, g])$ is the aggregation operation result of these elements of $S$, then the 2-tuple linguistic information is obtained by the following function $f$ :

$$
\begin{aligned}
f:[0, g] & \longrightarrow S \times[-0.5,0.5] \\
f(\beta) & =\left(s_{i}, \alpha\right), \quad \begin{cases}s_{i}, & i=\operatorname{round}(\beta) \\
\alpha=\beta-i, & \alpha \in[-0.5,0.5]\end{cases}
\end{aligned}
$$

where round is a rounding operation and $i \in[0, g]$.

Correspondingly, the real number $\beta$ can be obtained by the 2-tuple linguistic information according to the following function $f^{-1}$.

$$
\begin{aligned}
f^{-1}: S \times[-0.5,0.5] & \longrightarrow[0, g] \\
f^{-1}\left(s_{i}, \alpha\right) & =i+\alpha=\beta \\
s_{i} & \in S \Longrightarrow\left(s_{i}, 0\right) \in \bar{S}
\end{aligned}
$$

where formula (7) represents the conversion between a linguistic term and a 2-tuple linguistic consists in adding a value 0 as symbolic translation.

Definition 2. Let $X=\left\{\left(s_{1}, \alpha_{1}\right),\left(s_{2}, \alpha_{2}\right), \ldots,\left(s_{n}, \alpha_{n}\right)\right\}$ be a set of 2 -tuples, let $w=\left(w_{1}, w_{2}, \ldots, w_{n}\right)^{\mathrm{T}}$ be the weight vector, where $w_{i} \in[0,1], i=1,2, \ldots, n, \sum_{i=1}^{n} w_{i}=1$, and the 2 tuple weighted average (TWA) operator is defined as

$$
\operatorname{TWA}(X)=f\left(\frac{1}{n} \sum_{j=1}^{n} w_{j} \triangle^{-1}\left(r_{j}, \alpha_{j}\right)\right)=\left(\frac{1}{n} \sum_{j=1}^{n} w_{j} \beta_{j}\right)
$$



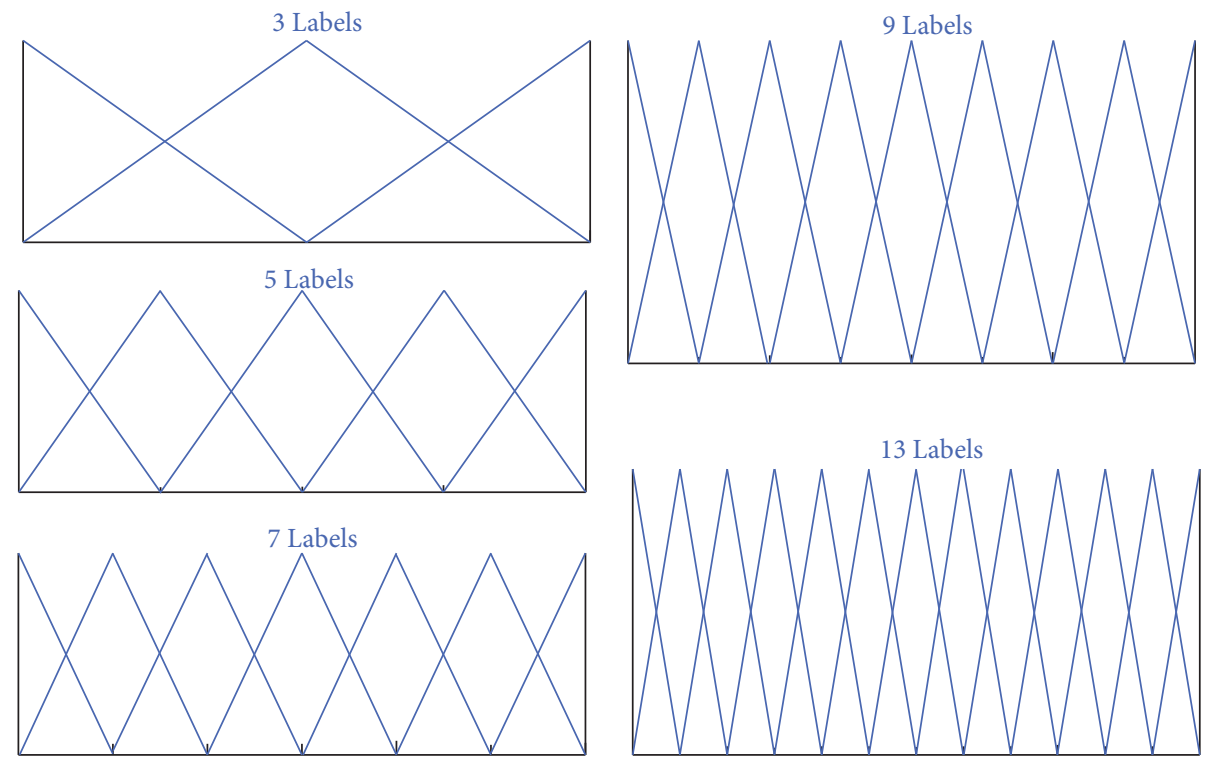

FIgURE 4: Common linguistic hierarchies.

As information aggregation plays a very significant role in the process of making decision, aggregation operators with 2-tuple linguistic information have attracted many scholars' attention. If the 2-tuples are from different linguistic term sets, they cannot be aggregated directly and should be conducted tedious transformation before aggregation operation, to avoid complicated computation, we proposed some aggregation operators with interval-valued 2-tuple linguistic information. Besides, we discuss their desired definition.

Definition 3. Let the linguistic evaluation set be $S=$ $\left\{s_{0}, s_{1}, \ldots, s_{g}\right\},\left[\left(s_{i}, \alpha_{1}\right),\left(s_{j}, \alpha_{2}\right)\right]$ which is called the interval 2tuple linguistic, where $s_{i}$ and $s_{j}$ belong to the evaluation set $S$ and $i \leq j, \alpha_{1}<\alpha_{2}$. The interval number $\left[\beta_{1}, \beta_{2}\right]\left(\beta_{1}, \beta_{2} \in\right.$ $\left.[0,1], \beta_{1} \leq \beta_{2}\right)$ can be obtained by the following function $f$ :

$$
\begin{array}{r}
f\left(\left[\beta_{1}, \beta_{2}\right]\right)=\left[\left(s_{i}, \alpha_{1}\right),\left(s_{j}, \alpha_{2}\right)\right], \\
\begin{cases}s_{i} & i=\operatorname{round}\left(\beta_{1} * g\right) \\
s_{j} & j=\operatorname{round}\left(\beta_{2} * g\right) \\
\alpha_{1}=\beta_{1}-\frac{i}{g}, & \alpha_{1} \in\left[-\frac{0.5}{g}, \frac{0.5}{g}\right] \\
\alpha_{2}=\beta_{2}-\frac{j}{g}, & \alpha_{2} \in\left[-\frac{0.5}{g}, \frac{0.5}{g}\right]\end{cases}
\end{array}
$$

On the contrary, the interval 2-tuple linguistic $\left[\left(s_{i}, \alpha_{1}\right),\left(s_{j}, \alpha_{2}\right)\right]$ can be converted into interval numbers by function $f^{-1}$ :

$$
\begin{aligned}
f^{-1} & {\left[\left(s_{i}, \alpha_{1}\right),\left(s_{j}, \alpha_{2}\right)\right]=\left[\frac{i}{g}+\alpha_{1}, \frac{j}{g}+\alpha_{2}\right] } \\
= & {\left[\beta_{1}, \beta_{2}\right] }
\end{aligned}
$$

Particularly, if $s_{i}=s_{j}$ and $\alpha_{i}=\alpha_{j}$, then the interval 2tuple linguistic variable becomes a 2 -tuple linguistic variable.

Definition 4. Let $X=\left\{\left[\left(s_{1}, \alpha_{1}\right),\left(s_{1}^{\prime}, \alpha_{1}^{\prime}\right)\right],\left[\left(s_{2}, \alpha_{2}\right),\left(s_{2}^{\prime}, \alpha_{2}^{\prime}\right)\right]\right.$, $\left.\ldots,\left[\left(s_{n}, \alpha_{n}\right),\left(s_{n}^{\prime}, \alpha_{n}^{\prime}\right)\right]\right\}$ be a set of 2 -tuples, let $w=$ $\left(w_{1}, w_{2}, \ldots, w_{n}\right)^{\mathrm{T}}$ be the weight vector, where $w_{i} \in[0,1], i=$ $1,2, \ldots, n, \sum_{\mathrm{i}=1}^{n} w_{i}=1$, and the interval 2 -tuple weighted average (ITWA) operator is defined as

$$
\begin{aligned}
& \text { ITWA }\left\{\left[\left(s_{1}, \alpha_{1}\right),\left(s_{1}^{\prime}, \alpha_{1}^{\prime}\right)\right],\left[\left(s_{2}, \alpha_{2}\right),\left(s_{2}^{\prime}, \alpha_{2}^{\prime}\right)\right], \ldots,\right. \\
& \left.\quad\left[\left(s_{n}, \alpha_{n}\right),\left(s_{n}^{\prime}, \alpha_{n}^{\prime}\right)\right]\right\} \\
& \quad=f\left[\sum_{i=1}^{n} w_{i} f^{-1}\left(s_{i}, \alpha_{i}\right), \sum_{i=1}^{n} w_{i} f^{-1}\left(s_{i}^{\prime}, \alpha_{i}^{\prime}\right)\right]
\end{aligned}
$$

This approach is introduced to deal with information assessed in different linguistic scales by using the extension principle and the interval 2-tuple linguistic representation model. It is a computing model as shown in Figure 5

In summary, the process of determining the weight of CRs is as follows.

Step 1. Set the linguistic evaluation set $S=\left\{s_{0}, s_{1}, \ldots, s_{g}\right\}$.

Step 2. Evaluate requirement $i$ and requirement $j$ according to evaluator $R(k)$, and get the measure value $\left[u_{i j}^{k}, v_{i j}^{k}\right]$, where $k=1,2, \ldots, l, u_{i j}^{k}, v_{i j}^{k} \in S, i, j=1,2, \ldots, n$.

Step 3. Obtain the linguistic complementary judgment matrix $R_{k}=\left(u_{i j}^{k}, v_{i j}^{k}\right)_{n \times n}$ according to the measure value, and the weight vector of the evaluator is $w_{k}=$ $\left(w_{1}, w_{2}, \ldots, w_{l}\right)$, where $\sum_{k=1}^{l} w_{k}=1$. 
Step 4. Convert the linguistic complementary judgment matrix $R_{k}$ to the interval 2-tuple linguistic judgment matrix $R_{k}^{\prime}$ :

$$
R_{k}^{\prime}=\left(\left[\left(u_{i j}^{k}, 0\right),\left(v_{i j}^{k}, 0\right)\right]\right)_{n \times n}
$$

Step 5. The interval 2-tuple linguistic $\left[\left(u_{i j}^{k}, 0\right),\left(v_{i j}^{k}, 0\right)\right]$ is transformed into the corresponding interval number $\left[c_{i j}^{k}, d_{i j}^{k}\right]$ by the inverse function $f^{-1}$.

Step 6. Aggregate the number of intervals $\left[c_{i j}^{k}, d_{i j}^{k}\right]$ and get the interval 2-tuple linguistic comprehensive evaluation matrix $\widetilde{R}:$

$$
\widetilde{R}=\left(\left[c_{i j}, d_{i j}\right]\right)_{n \times n}=\left(\left[\sum w_{k} c_{i j}^{k}, \sum w_{k} d_{i j}^{k}\right]\right)_{n \times n}
$$

Step 7. $R=\left(\left[s_{i j}, s_{i j}^{\prime}\right]\right)_{m \times n}$ is the evaluation matrix, where $i=1,2, \ldots, m ; j=1,2, \ldots n$, then the comprehensive weight interval of the evaluation object $i$ is

$$
\theta_{i}=\left[\gamma_{i}, \gamma_{i}^{\prime}\right]=\left[\frac{\left(\sum_{i=1}^{n} s_{i j}\right)}{n}, \frac{\left(\sum_{i=1}^{n} s_{i j}^{\prime}\right)}{n}\right]
$$

Step 8. If the evaluation object $i$ is not inferior to the evaluation object $k$ and $\theta_{i} \geq \theta_{k}(i, k=1,2, \ldots, m)$, then get $p_{i k}$ by pairwise comparison according to the comprehensive evaluation value from Step 7, and the formula is as follows:

$$
\begin{aligned}
p_{i k} & =p\left(\theta_{i} \geq \theta_{k}\right) \\
& =\max \left\{1-\max \left\{\frac{\gamma_{k}^{\prime}-\gamma_{i}}{\left(\gamma_{i}^{\prime}-\gamma_{i}\right)+\left(\gamma_{k}^{\prime}-\gamma_{k}\right)}, 0\right\}, 0\right\}
\end{aligned}
$$

Then obtain the following probability matrix $P$ :

$$
P=\left(P_{i k}\right)_{m \times n}=\left[\begin{array}{cccc}
P_{11} & P_{12} & \cdots & P_{1 m} \\
P_{21} & P_{22} & \cdots & P_{2 m} \\
\vdots & \vdots & \vdots & \vdots \\
P_{m 1} & P_{m 2} & \cdots & P_{m m}
\end{array}\right]
$$

Among them, the rank vector of possible degree matrix is obtained:

$$
\varphi_{i}=\frac{\sum_{k=1}^{m} P_{i k}+m / 2-1}{m(m-1)}
$$

Step 9. We obtain the ranking vector $\varphi_{i}$ of the probability matrix $P$. According to the size of $\varphi_{i}$ obtain the weights of different CRs.

The flow chart based on the interval 2-tuple linguistic information is shown in Figure 5.

\section{Selection of Innovative Schemes Based on Prospect Theory}

Due to restrictions on resources such as technology, cost, and equipment, the innovation efficiency is not obvious in CCPI design process. Therefore, the prospects theory is proposed in the case of customer demand which has been identified, which considers the company's technology, cost, advanced equipment, and the conflict between the demand and the impact of psychological factors of the customers. According to the customer satisfaction and the expected value of each attribute of the product, we can calculate the comprehensive prospect value and determine the optimal product scheme by using the prospect theory.

3.1. Gains and Loss Value of Product Attributes. Firstly, we regard aspiration-levels as reference points. Then, gains and losses of alternatives are obtained by the corresponding formulas. Since attribute values are represented in the three types: crisp number, interval number, and intuitive trapezoidal fuzzy number, there are three possible types for comparing an attribute value with an aspiration level (see Figure 6),

In Figure 6, type one represents the situation that attribute value is crisp numbers; type two represents the situation that attribute values are interval numbers; type three represents the situation that attribute values are intuitive trapezoidal fuzzy number.

Assuming that aspiration level is clear number, the attribute value has three types: clear number, interval number, and intuitive trapezoidal fuzzy number. For the three types of attribute values, the specific description is as follows: where $x_{i l}$ is representing the value of attribute $l$ of supplier $i$ (see Tables 5 and 6).

(1) If $I_{l} \in I^{C}$, let $x_{i l}=x_{i l}^{\prime}$, where $x_{i l}^{\prime}$ is clear number, and $i \in M, l \in N^{K}$.

(2) If $I_{l} \in I^{\mathrm{Q}}$, let $x_{i l}=\bar{x}_{i l}$, where $\bar{x}_{i l}$ is an interval number $\bar{x}_{i l}=\left[x_{i l}^{1}, x_{i l}^{2}\right]$. Assuming that the attribute values are randomly obtained in the interval $\left[x_{i l}^{1}, x_{i l}^{2}\right]$ and are uniformly distributed, the probability density function is $f_{i l}(x)$ :

$$
f_{i l}(x)=\left\{\begin{array}{ll}
\frac{1}{x_{i l}^{2}-x_{i l}^{1}}, & x_{i l}^{1} \leq x \leq x_{i l}^{2} \\
0, & \text { other, }
\end{array} \quad i \in M, l \in N\right.
$$

(3) If $I_{j} \in I^{F}$, let $x_{i l}=\tilde{x}_{i l}$, where $\tilde{x}_{i l}$ is intuitive trapezoidal fuzzy number $\tilde{x}_{i l}=$ $\left\langle\left(\left[a_{i l}, b_{i l}, c_{i l}, d_{i l}\right] ; \phi_{x}\right),\left(\left[a_{i l 1}, b_{i l}, c_{i l}, d_{i l 1}\right] ; \tau_{x}\right)\right\rangle$, and $0 \leq \phi_{x} \leq 1$, $0 \leq \tau_{x} \leq 1, \phi_{x}+\tau_{x} \leq 1, a_{i l}, b_{i l}, c_{i l}, d_{i l}, a_{i l 1}, d_{i l 1} \in R$, and the membership function $\phi_{i l}(x)$ is as shown:

$$
\phi_{i l}(x)=\left\{\begin{array}{ll}
\frac{x-a_{i l}}{b_{i l}-a_{i l}}, & a_{i l} \leq x \leq b_{i l} \\
\phi_{i l}, & b_{i l} \leq x \leq c_{i l} \\
\frac{d_{i l}-x}{d_{i l}-c_{i l}}, & c_{i l} \leq x \leq d_{i l} \\
0, & \text { others }
\end{array} \quad i \in M, l \in N\right.
$$

If $\left[a_{i l}, b_{i l}, c_{i l}, d_{i l}\right]=\left[a_{i l 1}, b_{i l}, c_{i l}, d_{i l 1}\right]$, the intuitionistic trapezoidal fuzzy number $\widetilde{x}_{i l}=\left(\left[a_{i l}, b_{i l}, c_{i l}, d_{i l}\right] ; \phi_{x}, \tau_{i l}\right)$.

3.2. Calculating the Gains and Losses Value. Let the expect value $e=\left(e_{1}, e_{2}, \ldots, e_{l}\right)$ of customers as the reference point in 


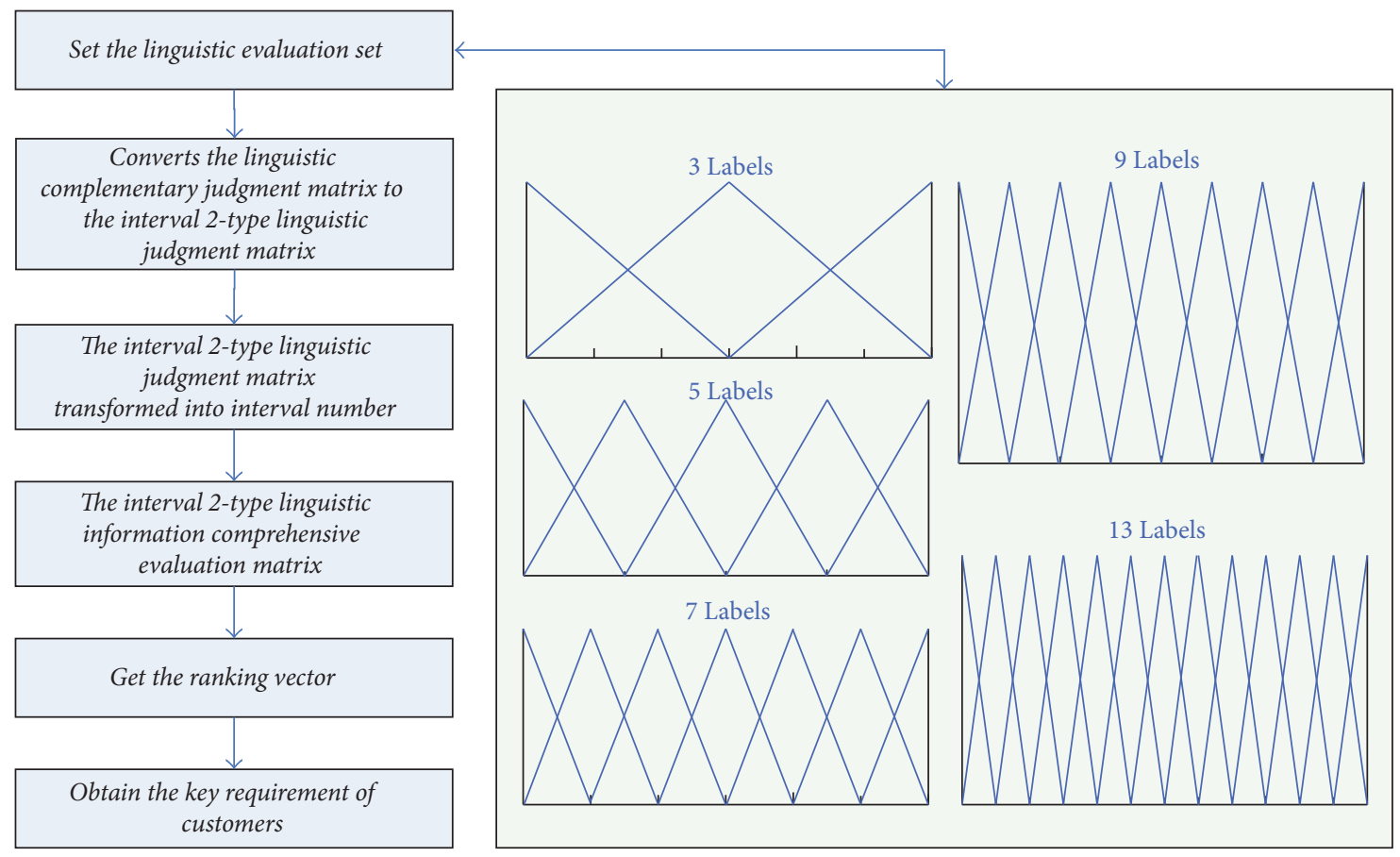

FIGURE 5: The flow chart based on the interval 2-tuple linguistic information.

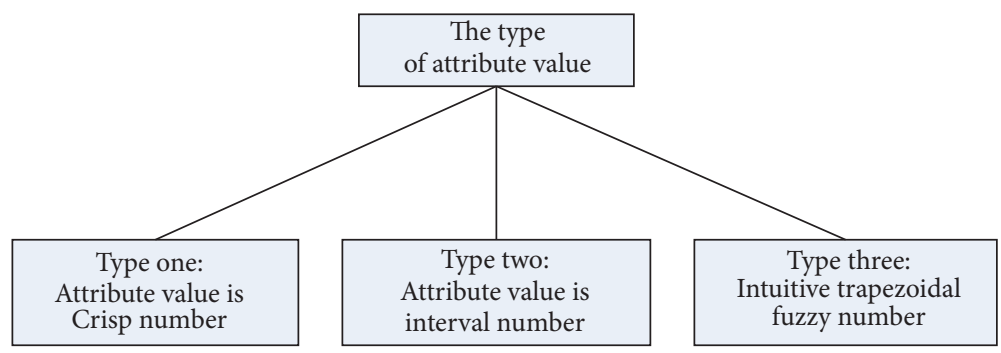

FIGURE 6: The types of attribute value.

TABLE 5: Possible cases of position relationships between attribute value and aspiration level.

\begin{tabular}{|c|c|c|}
\hline Type & Cases & Position relationships between attribution value and aspiration level \\
\hline \multirow{2}{*}{ Type one } & Case one (a) $x_{i l} \geq e_{l}$ & $\dot{x}_{i l}$ \\
\hline & Case one $(b) x_{i l}<e_{l}$ & $\ddot{x}_{i l}$ \\
\hline \multirow{3}{*}{ Type two } & Case two $(a) x_{i l}^{1}>e_{l}$ & $\dot{e}_{l} \quad x_{i l}^{1} \quad x_{i l}^{2}$ \\
\hline & Case two $(b) x_{i l}^{1} \leq e_{l} \leq x_{i l}^{2}$ & $x_{i l}^{1} \quad e_{l} \quad x_{i l}^{2}$ \\
\hline & Case two (c) $x_{i l}^{2}<e_{l}$ & $x_{i l}^{1}$ \\
\hline \multirow{3}{*}{ Type three } & Case three $(a) e_{l}<a_{i l}$ & $e_{l} \quad a_{i l}$ \\
\hline & Case three $(b) a_{i l} \leq e_{l} \leq d_{i l}$ & $a_{i l}$ \\
\hline & Case three $(c) d_{i l}<e_{l}$ & $a_{i l}$ \\
\hline
\end{tabular}


TABLE 6: Variable symbol description.

\begin{tabular}{lc}
\hline Variable & Meaning \\
\hline$S=\left\{S_{1}, S_{2}, \ldots, S_{i}, \ldots, S_{m}\right\}$ & A set of $m$ alternative products \\
$I=\left\{I_{1}, I_{2}, \ldots, I_{i}, \ldots, I_{l}\right\}$ & The set of product attributes \\
$E=\left(e_{1}, e_{2}, \ldots, e_{n}\right)$ & Expectation vector of requirements \\
$I^{\mathrm{C}}$ & Attribute sets whose attribute values are distinct numbers \\
$I^{\mathrm{Q}}$ & Attribute sets whose attribute values are interval numbers \\
$I^{F}$ & Attribute sets whose attribute values are intuitionistic trapezoidal fuzzy numbers \\
$N=\{1,2, \ldots, n\}$ & Product attribute sets \\
$M=\{1,2, \ldots, m\}$ & Scheme numbers \\
\hline
\end{tabular}

TABLE 7: Calculation formula when the attribute value is a clear number.

\begin{tabular}{lcc}
\hline $\begin{array}{l}\text { Attribute } \\
\text { type }\end{array}$ & $\begin{array}{c}\text { The relationship between attribute value } \\
\text { and the reference point }\end{array}$ & $\begin{array}{c}\text { Calculation of gain }\left(G_{i l}\right) \text { and loss value } \\
\left(L_{i l}\right)\end{array}$ \\
\hline & $x_{i l}^{\prime}<e_{l}$ & $G_{i l}=0, \quad i \in M, l \in N(20)$ \\
$I_{l} \in I^{K}$ & & $L_{i l}=x_{i l}^{\prime}-e_{i l} \quad i \in M, l \in N(21)$ \\
& $x_{i l}^{\prime} \geq e_{l}$ & $G_{i l}=x_{i l}^{\prime}-e_{i l} \quad i \in M, l \in N(22)$ \\
$L_{i l}=0 \quad i \in M, l \in N(23)$
\end{tabular}

this paper. Then, calculate the gains and loss of each attribute value relative to the reference point. When the attribute value is a clear number, we obtain the gains and losses value of product attribute according to the calculation formula shown in Table 7.

When the attribute value is the number of intervals, according to the attribute value and the position of the reference point, the formula of each attribute value of the innovation scheme is shown in Table 8.

When the attribute value is intuitionistic trapezoidal fuzzy number, according to the relative position of the attribute value and the reference point, the formula of each attribute value of the innovation scheme is shown in Table 9.

3.3. Calculating the Prospect Values and Ranking. For the gain matrix $G_{t}=\left[G_{i l}\right]_{m * n}$ and the loss matrix $L_{t}=\left[L_{i l}\right]_{m * n}$ of each scheme, calculate the prospective value of the candidate product. Based on prospect theory, the value of gain matrix $G_{i l}$ is

$$
v_{i l}^{(+)}=\left(G_{i l}\right)^{a}, \quad i \in M, l \in N
$$

The value $V_{i l}^{(-)}$of loss is

$$
v_{i l}^{(-)}=-\lambda\left(-L_{i l}\right)^{b}, \quad i \in M, l \in N
$$

where $a$ and $b$ represent the degree of concavity and convexity of the loss region and gain region of the value function, $0<a<1,0<b<1$, and $\lambda$ indicates the loss degree of the decision maker $(\lambda>1)$. Among them, $a$ and $b$ greater, decision-makers incline to risk more, and $\lambda$ greater, the ability of decision-makers to avoid losses is greater.

Due to the difference in the dimension of the product attribute value is so large that we use the range transformation method to reduce the dimension; the new gain and loss values of each innovation scheme are obtained by formulas (38)(39).

$$
\begin{aligned}
V_{i l}^{(+)} & =\frac{v_{i l}^{(+)}-\min v_{i l}^{(+)}}{\max v_{i l}^{(+)}-\min v_{i l}^{(+)}} \\
V_{i l}^{(-)} & =\frac{v_{i l}^{(-)}-\min v_{i l}^{(-)}}{\max v_{i l}^{(-)}-\min v_{i l}^{(-)}} \\
V_{i l} & =V_{i l}^{(+)}-V_{i l}^{(-)}, \quad i \in M, \quad l \in N
\end{aligned}
$$

According to formula (40), the prospect decision matrix can be obtained.

The flow chart based on prospect theory is shown in Figure 7.

\section{Case Study}

In order to enhance market competitiveness, an Electronic Manufacturing Enterprise in Xi'an has designed five innovation schemes for mobile phones. Moreover, this enterprise uses the proposed method to determine the optimal scheme. According to the mobile phone function, it has identified 35 types of CRs (Appendix A.1), and a market survey of whether or not to provide the demand item based on the Kano model is conducted to screen out ten relatively important requirements towards customer satisfaction (Appendix A.3). Five experts $R^{k}(k=1,2,3,4,5)$ are invited to participate in the evaluation of the importance of CRs that affected customer satisfaction. As such, experts $R^{1}$ and $R^{2}$ use nine elements of the linguistic evaluation set $S=\left\{s_{0}, s_{1}, s_{2}, s_{3}, s_{4}, s_{5}, s_{6}, s_{7}, s_{8}\right\}$, experts $R^{3}$ and $R^{4}$ employ even elements of the linguistic evaluation set $X=\left\{x_{0}, x_{1}, x_{2}, x_{3}, x_{4}, x_{5}, x_{6}\right\}$, and last, 
TABLE 8: The calculation formula when the attribute value is the interval number.

\begin{tabular}{ccc}
\hline Attribute type & The relationship between attribute value and the reference point & Calculation of gain $\left(G_{i l}\right)$ and loss value $\left(L_{i l}\right)$ \\
\hline$x_{i l}^{2}<e_{l}$ & $G_{i l}=0, \quad i \in M, l \in N \quad(24)$ \\
& $x_{i l}^{1} \leq e_{l} \leq x_{i l}^{2}$ & $L_{i l}=\int_{x_{i l}^{1}}^{x_{i l}^{2}}\left(x-e_{l}\right) f_{i l}(x) d x \quad i \in M, l \in N \quad(25)$ \\
& $x_{i l}^{1}>e_{l}$ & $G_{i l}=\int_{e_{l}}^{x_{i l}^{2}}\left(x-e_{l}\right) f_{i l}(x) d x \quad i \in M, l \in N \quad(26)$ \\
& $L_{i l}=\int_{x_{i l}^{1}}^{e_{l}}\left(x-e_{l}\right) f_{i l}(x) d x \quad i \in M, l \in N \quad(27)$ \\
& $G_{i l}=\int_{x_{i l}^{1}}^{x_{i l}^{2}}\left(x-e_{l}\right) f_{i l}(x) d x \quad i \in M, l \in N \quad(28)$ \\
& $L_{i l}=\int_{x_{i l}^{1}}^{x_{i l}^{2}}\left(e_{l}-x\right) f_{i l}(x) d x \quad i \in M, l \in N \quad(29)$
\end{tabular}

TABLE 9: Calculation formula for attribute values as intuitionistic trapezoidal fuzzy numbers.

\begin{tabular}{|c|c|c|c|}
\hline Attribute type & The relationship between attribute value and the reference point & \multicolumn{2}{|c|}{ Calculation of gain $\left(G_{i l}\right)$ and loss value $\left(L_{i l}\right)$} \\
\hline \multirow{4}{*}{$I_{l} \in I^{F}$} & $e_{l} \leq a_{i l}$ & $\begin{array}{c}G_{i l}=\int_{a_{i l}}^{d_{i j}}\left(x-e_{l}\right) \phi_{i l}(x) d x \quad i \in M, l \in N \\
L_{i l}=0 \quad i \in M, l \in N\end{array}$ & $\begin{array}{l}(30) \\
(31)\end{array}$ \\
\hline & $a_{i l} \leq e_{l} \leq d_{i l}$ & $G_{i l}=\int_{e_{l}}^{d_{i l}}\left(x-e_{l}\right) \phi_{i l}(x) d x \quad i \in M, l \in N$ & $(32)$ \\
\hline & $v_{i l}=4=v_{i l}$ & $L_{i l}=\int_{a_{i l}}^{e_{l}}\left(x-e_{l}\right) \phi_{i l}(x) d x \quad i \in M, l \in N$ & (33) \\
\hline & $e_{l} \geq d_{i l}$ & $\begin{array}{c}G_{i l}=0 \quad i \in M, \quad l \in N \\
L_{i l}=\int_{a_{i l}}^{d_{i l}\left(x-e_{l}\right) \phi_{i l}(x) d x \quad i \in M, l \in N}\end{array}$ & $\begin{array}{l}(34) \\
(35)\end{array}$ \\
\hline
\end{tabular}

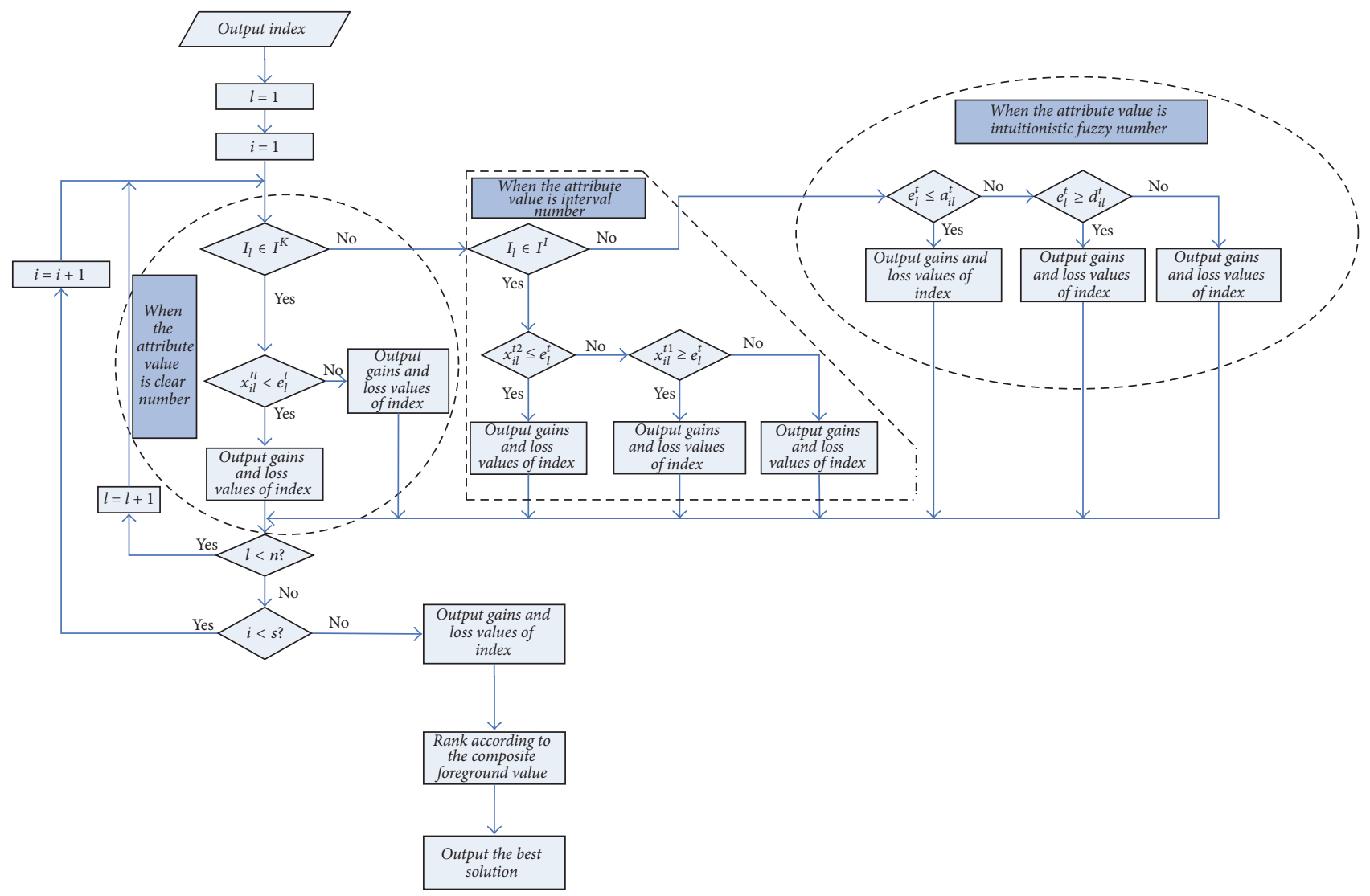

FIGURE 7: The flow chart based on prospect theory. 


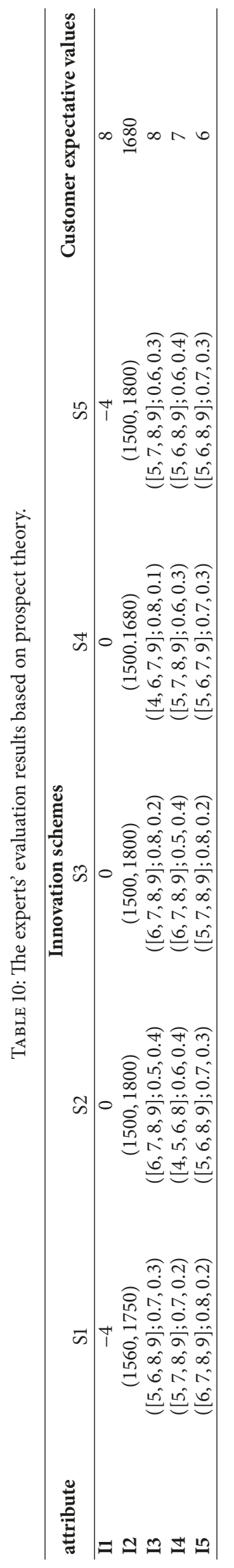


TABLE 11: The gain value of the innovation schemes.

\begin{tabular}{lcccccc}
\hline \multirow{2}{*}{ Attribute } & \multicolumn{9}{c}{ The gain value of the innovation schemes } & Customer expectative values \\
& $\mathrm{S} 1$ & $\mathrm{~S} 2$ & $\mathrm{~S} 3$ & $\mathrm{~S} 4$ & $\mathrm{~S} 5$ & 8 \\
I1 & 0 & 0 & 0 & 0 & 24 & 1680 \\
I2 & $245 / 19$ & 24 & 24 & 0 & $1 / 6$ & 8 \\
I3 & $21 / 10$ & $1 / 6$ & $13 / 30$ & $1 / 12$ & $29 / 30$ & 7 \\
I4 & $61 / 60$ & $1 / 12$ & $11 / 12$ & $29 / 30$ & $77 / 30$ & 6 \\
I5 & $27 / 10$ & $77 / 30$ & $167 / 60$ & $51 / 20$ & \\
\hline
\end{tabular}

TABLE 12: The loss value of the innovation schemes.

\begin{tabular}{lcccccc}
\hline \multirow{2}{*}{ Attribute } & \multicolumn{9}{c}{ The loss value of the innovation schemes } & Customer expectative values \\
& $\mathrm{S} 1$ & $\mathrm{~S} 2$ & $\mathrm{~S} 3$ & $\mathrm{~S} 4$ & $\mathrm{~S} 5$ & 8 \\
I1 & -4 & 0 & 0 & 0 & -4 & 1680 \\
I2 & $-720 / 19$ & -54 & -54 & -90 & -54 & 8 \\
I3 & $-9 / 2$ & $-11 / 12$ & $-4 / 3$ & $-257 / 60$ & $-59 / 30$ & 7 \\
I4 & $-2 / 3$ & $-149 / 60$ & $-1 / 6$ & $-2 / 3$ & $-2 / 3$ & 6 \\
I5 & 0 & $-1 / 6$ & $-1 / 12$ & 0 & $-1 / 6$ & \\
\hline
\end{tabular}

experts $R^{5}$ adopt five elements of the linguistic evaluation set $Y=\left\{y_{0}, y_{1}, y_{2}, y_{3}, y_{4}\right\}$. Experts' opinions are shown in Appendix B.1. The weight vector corresponding to the experts' opinions is $w=(0.25,0.25,0.2,0.2,0.1)$, and finally five key attributes are determined as being the most important product attributes in the five innovative evaluation schemes (see Table 10). These key attributes are the following: operating system (I1), CPU core count (I2), antitheft tracking (I3), fingerprint sensor (I4), and battery capacity (I5). Based on the prospect theory, the customer's expectation value of a product attribute is taken as the reference point, and the proposed method is used to determine the optimal scheme. The calculation steps are discussed in the following.

Step 1. Obtain the five experts' linguistic evaluation values with respect to the five attributes of the above-mentioned five innovation schemes (Appendix B.1).

Step 2. Determine the gain and loss values of each innovation scheme based on formula (19)-(36), and the results are shown in Tables 11 and 12.

Step 3. Determine the new gain and loss values of each innovation scheme when the influence of the dimension is eliminated according to the formula ((37) and (38)); the results are shown in Tables 13 and 14.

Step 4. Obtain the prospect value of each attribute value as shown in Table 15.

Step 5. Calculate the weights of the CRs and rank.

It can be observed from the weight of the indicators $\varphi=(0.114,0.112,0.110,0.105,0.104)$ (Appendix B.5) that the standardization of the weight of the indicators was $\omega=$ $(0.2092,0.2055,0.2018,0.1927,0.1908)$.
According to the formula (40), the comprehensive prospect of each scheme is $u=(-0.6910,-0.6203,-0.6118$, $-0.7153,-0.5989)$, so the merits of the innovative program are $S_{5}>S_{3}>S_{2}>S_{1}>S_{4}$.

The proposed hybrid method provides a systemic analytical model for apperceiving the key customer requirements and obtaining the optimal innovation schemes. According to the Kano model, ten relatively important requirements towards customer satisfaction are screened out (Appendix A.3); combined with experts' opinion, five indicators, i.e., operating system (I1), CPU core count (I2), antitheft tracking (I3), fingerprint sensor (I4), and battery capacity (I5), are determined as the most important indicators. And then with the help of interval 2-tuple linguistic, we easily obtain the weights of these indicators. Finally, based on the prospect theory, the comprehensive prospect value of each scheme is calculated; it is suggested that the optimal innovative scheme is $S_{5}$.

\section{Comparative Analysis}

In order to verify the validity of the developed method, the Technique for Order of Preference by Similarity to an Ideal Solution (TOPSIS) (Gangurde et al. 2013) and the Vlse Kriterjumska Optimizacija I Kompromisno Resenje (VIKOR) (Qin et al. 2015) were compared with the methods proposed in this paper (see Tables 16-18).

From Table 16, it is obvious that $Q_{5}>Q_{1}>Q_{3}>Q_{4}>$ $Q_{2}$, but for the fact that $0.18-0.062<1 /(5-1)$ and by the formula $0.18-0.062<1 /(m-1)$, we can know that $S_{1}, S_{2}, S_{3}$, $S_{4}$, and $S_{5}$ are all close to the ideal scheme.

From Table 18, we can see that the sorted results are quite different, the result of the proposed MCDM model based on prospect theory is $S_{5}>S_{3}>S_{2}>S_{1}>S_{4}$, the TOPSIS method obtains result as $S_{5}>S_{4}>S_{1}>S_{3}>S_{2}$, and the 
TABLE 13: The new gain value of the innovation schemes after eliminated influence of dimension.

\begin{tabular}{lcccccc}
\hline \multirow{2}{*}{ Attribute } & \multicolumn{6}{c}{ The new gain value of the innovation schemes } \\
& S1 & S2 & S3 & S4 & S5 & Customer expectative values \\
\hline I1 & 0.000 & 0.000 & 0.000 & 0.112 & 0.000 & 1.000 \\
I2 & 0.579 & 1.000 & 1.000 & 0.000 & 0.013 & 1680 \\
I3 & 0.117 & 0.013 & 0.029 & 0.007 & 0.059 & 8 \\
I4 & 0.062 & 0.007 & 0.057 & 0.059 & 0.140 & 7 \\
I5 & 0.146 & 0.140 & 0.150 & 0.139 & 6 \\
\hline
\end{tabular}

TABLE 14: The new loss value of the innovation schemes after eliminated influence of dimension.

\begin{tabular}{lcccccc}
\hline \multirow{2}{*}{ Attribute } & \multicolumn{7}{c}{ The new loss value of the innovation schemes } & Customer expectative values \\
& S1 & S2 & S3 & S4 & S5 & 8 \\
I1 & 0.935 & 1.000 & 1.000 & 1.000 & 0.935 & 1680 \\
I2 & 0.533 & 0.362 & 0.362 & 0.000 & 0.362 & 8 \\
I3 & 0.928 & 0.982 & 0.975 & 0.931 & 0.985 & 7 \\
I4 & 0.987 & 0.958 & 0.996 & 0.987 & 0.996 & 6 \\
I5 & 1.000 & 0.996 & 0.998 & 1.000 & & 8 \\
\hline
\end{tabular}

TABLE 15: The prospect values of the innovation schemes.

\begin{tabular}{|c|c|c|c|c|c|c|}
\hline \multirow{2}{*}{ Attribute } & \multicolumn{5}{|c|}{ The prospect value of the innovation schemes } & \multirow{2}{*}{ Customer expectative values } \\
\hline & S1 & S2 & S3 & S4 & S5 & \\
\hline I1 & -0.935 & -1.000 & -1.000 & -0.888 & -0.935 & 8 \\
\hline I2 & 0.046 & 0.638 & 0.638 & 0.000 & 0.638 & 1680 \\
\hline I3 & -0.811 & -0.970 & -0.946 & -0.925 & -0.953 & 8 \\
\hline I4 & -0.925 & -0.951 & -0.940 & -0.927 & -0.927 & 7 \\
\hline I5 & -0.854 & -0.856 & -0.848 & -0.861 & -0.856 & 6 \\
\hline
\end{tabular}

TABLE 16: The result of TOPSIS method.

\begin{tabular}{lccc}
\hline & & TOPSIS & \\
Scheme & The ideal solution & The negative solution & Similarity degree \\
\hline$S_{1}$ & 0.126 & 0.125 & 0.499 \\
$S_{2}$ & 0.051 & 0.003 & 0.05 \\
$S_{3}$ & 0.04 & 0.013 & 0.248 \\
$S_{4}$ & 0.131 & 0.139 & 0.514 \\
$S_{5}$ & 0.017 & 0.041 & 0.707 \\
\hline
\end{tabular}

TABLE 17: The result of VIKOR method.

\begin{tabular}{lccc}
\hline Scheme & VIKOR & $R_{i}$ & $Q_{i}$ \\
\hline$S_{1}$ & $U_{i}$ & 0.191 & 0.18 \\
$S_{2}$ & 0.367 & 0.209 & 1 \\
$S_{3}$ & 0.726 & 0.209 & 0.672 \\
$S_{4}$ & 0.491 & 0.206 & 0.706 \\
$S_{5}$ & 0.561 & 0.18 & 0.062 \\
\hline
\end{tabular}

TABLE 18: The results of the three methods.

\begin{tabular}{lr}
\hline Method & Evaluation results \\
\hline Prospect theory & $S_{5}>S_{3}>S_{2}>S_{1}>S_{4}$ \\
TOPSIS & $S_{5}>S_{4}>S_{1}>S_{3}>S_{2}$ \\
VIKOR & $S_{5} \approx S_{1} \approx S_{3} \approx S_{4} \approx S_{2}$ \\
\hline
\end{tabular}


TABle 19

\begin{tabular}{lcccc}
\hline 1 Camera & 2 Shell color & 3 E-mail & 4 Theoretical talk time & 5 Screen material \\
\hline 6 Battery capacity & 7 Theoretical standby time & 8 CPU count & 9 Operating system & 10 Key shape \\
11 Screen size & 12 GPS & 13 Shell material & 14 Internet & 15 Screen color \\
16 HDMI interface & 17 Radio & 18 Electronic dictionary & 19 Alarm clock & 20 No USB connected to the computer \\
21 USB & 22 Calendar & 23 Video & 24 Word & 25 Sound recorder \\
26 E-book & 27 Pinyin input & 28 Calculator & 29 Music & 30 Typewriting \\
31 Bluetooth & 32 Antitheft tracking & 33 Flashlight & 34 Fingerprint sensor & 35 Quick boot \\
\hline
\end{tabular}

TABle 20

\begin{tabular}{|c|c|c|c|c|c|c|c|}
\hline Numbering & Initial customer requirements & $\mathrm{A}$ & $\mathrm{O}$ & $\mathrm{M}$ & $\mathrm{I}$ & $\mathrm{R}$ & Belongs to the Kano category \\
\hline 1 & Camera & 0 & 0.236 & 0.5281 & 0.236 & 0 & M \\
\hline 2 & Shell color & 0.5236 & 0.3213 & 0.0112 & 0.1438 & 0 & A \\
\hline 3 & E-mail & 0 & 0.4202 & 0.0876 & 0.4921 & 0 & I \\
\hline 4 & Theoretical talk time & 0 & 0.218 & 0.1753 & 0.6067 & 0 & I \\
\hline 5 & Screen material & 0 & 0.1326 & 0.009 & 0.8584 & 0 & I \\
\hline 6 & Battery capacity & 0.2517 & 0.6371 & 0.0112 & 0.1 & 0 & $\mathrm{O}$ \\
\hline 7 & Theoretical standby time & 0 & 0.618 & 0.1101 & 0.2719 & 0 & $\mathrm{O}$ \\
\hline 8 & CPU count & 0.5124 & 0.3371 & 0.1326 & 0.018 & 0 & $\mathrm{O}$ \\
\hline 9 & Operating system & 0.6584 & 0.2135 & 0 & 0.1281 & 0 & A \\
\hline 10 & Key shape & 0.5461 & 0.3371 & 0.1169 & 0 & 0 & A \\
\hline 11 & Screen size & 0 & 0.8944 & 0.0225 & 0.0831 & 0 & $\mathrm{O}$ \\
\hline 12 & GPS & 0 & 0.1416 & 0.5281 & 0.3303 & 0 & M \\
\hline 13 & Shell material & 0 & 0.2629 & 0.0225 & 0.7146 & 0 & I \\
\hline 14 & Internet & 0 & 0.2494 & 0.4607 & 0.2899 & 0 & M \\
\hline 15 & Screen color & 0 & 0.3191 & 0.5348 & 0.1461 & 0 & M \\
\hline 16 & HDMI interface & 0 & 0.1708 & 0.0337 & 0.7888 & 0.0067 & I \\
\hline 17 & Radio & 0 & 0.1438 & 0.8292 & 0.0202 & 0.0067 & M \\
\hline 18 & Electronic dictionary & 0 & 0.036 & 0.7618 & 0.1753 & 0.027 & M \\
\hline 19 & Alarm clock & 0 & 0.164 & 0.4449 & 0.3843 & 0.0067 & M \\
\hline 20 & No USB connected to the computer & 0 & 0.173 & 0 & 0.8045 & 0.0225 & I \\
\hline 21 & USB & 0 & 0.0831 & 0.7775 & 0.1258 & 0.0135 & M \\
\hline 22 & Calendar & 0 & 0.1303 & 0.7258 & 0.1371 & 0.0067 & M \\
\hline 23 & Video & 0 & 0.0697 & 0.7124 & 0.1775 & 0.0404 & M \\
\hline 24 & Word & 0 & 0.4494 & 0.0449 & 0.5056 & 0 & I \\
\hline 25 & Sound recorder & 0 & 0.0944 & 0.4854 & 0.4135 & 0.0067 & M \\
\hline 26 & E-book & 0 & 0.0876 & 0 & 0.8989 & 0.0135 & I \\
\hline 27 & Pinyin input & 0 & 0.391 & 0.4652 & 0.1371 & 0.0067 & M \\
\hline 28 & Calculator & 0 & 0.1573 & 0.4449 & 0.3978 & 0 & M \\
\hline 29 & Music & 0 & 0.3034 & 0.5393 & 0.1573 & 0 & M \\
\hline 30 & Typewriting & 0 & 0.4315 & 0.0315 & 0.5371 & 0 & I \\
\hline 31 & Bluetooth & 0 & 0.2563 & 0.5486 & 0.1951 & 0 & M \\
\hline 32 & Anti-theft tracking & 0.6025 & 0.3 & 0.0028 & 0.0695 & 0 & A \\
\hline 33 & Flashlight & 0 & 0.3546 & 0.4369 & 0.2085 & 0 & M \\
\hline 34 & Fingerprint sensor & 0.47 & 0.2586 & 0.1089 & 0.1625 & 0 & $\mathrm{~A}$ \\
\hline 35 & Quick boot & 0 & 0.4863 & 0.3957 & 0.118 & 0 & $\mathrm{O}$ \\
\hline
\end{tabular}

TABle 21

\begin{tabular}{lcr}
\hline 1 Key shape & 2 Shell color & 3 Operating system \\
\hline 4 Screen size & 5 Theoretical standby time & 6 CPU count \\
7 Fingerprint sensor & 8 Battery capacity & 9 Antitheft tracking \\
10 Quick boot & & \\
\hline
\end{tabular}




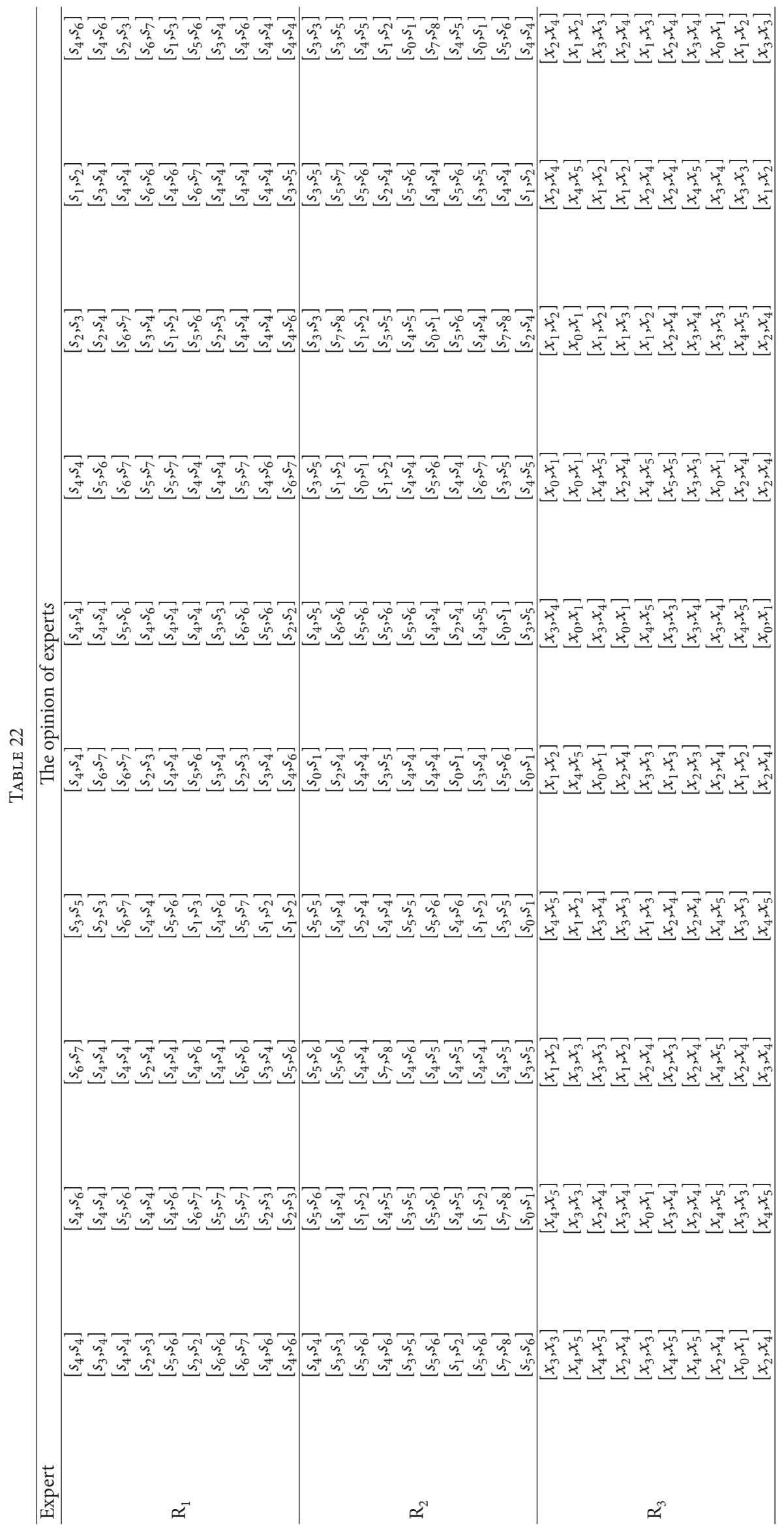




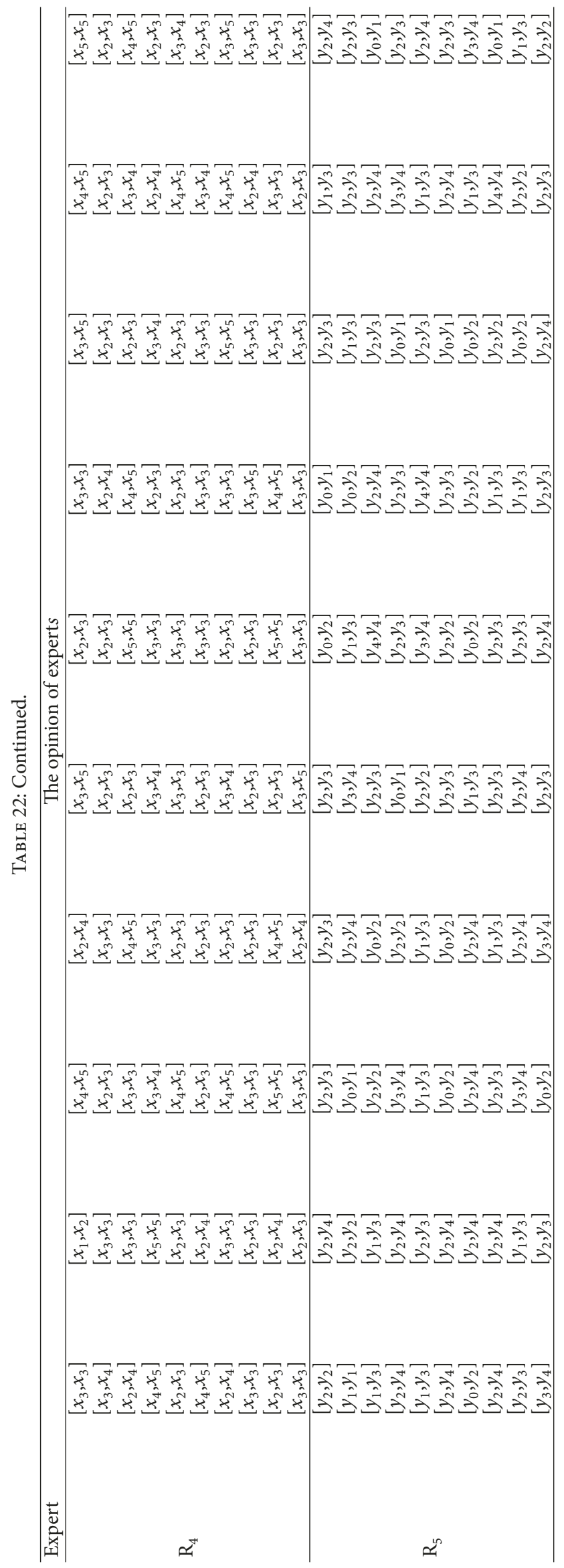


VIKOR method proves that there is no obvious difference between these innovative schemes. However, the optimal solution is always scheme $S_{5}$. From our results, we can see that the VIKOR method has a low degree of discrimination, and because the TOPSIS method relies solely on the data itself and is prone to reverse the phenomenon, so it is appropriate to evaluate the innovation schemes with the prospect theory. The prospect theory takes full account of decision-makers' psychological factors and behavioral science. It weighs both gains and losses, making the evaluation more comprehensive and objective. The decision result is closer to the actual situation and can better guide the production activities of enterprises.

\section{Conclusion}

Customer requirement is the initial information source and basis for product collaborative design and is key to the success of CCPI. Based on the fuzzy characteristics, as well as the dynamicity, diversity and individuation of CRs, a Kano model was constructed to identify and filter the initial requirements of customers in this paper; secondly, the weights of CRs were determined by the proposed interval 2-tuple linguistic representation model; finally, a comprehensive evaluation for the innovation schemes was given based on the prospect theory. In this process, some practical results have been obtained.

(1) The Kano model focuses on the analysis of factors that affect customer satisfaction. Through this model, we are able to capture the product attributes which can greatly improve customer satisfaction.

(2) Interval 2-tuple linguistic representation model is more accurate when expressing the vague language of customers and experts. In addition, it is a great advantage to accurately convert the decision-makers' linguistic information due to little information loss.

(3) This paper introduces the prospect theory into the process of CCPI, from the perspective of product design options, and considers the subjective attitude of decisionmakers fully. The scheme chosen based on the prospect theory is more scientific and makes the actual process of decision-making more efficient.

\section{Appendix}

\section{A. Customer Requirements Based on Kano Model}

A.1. Initial Customer Requirements. See Table 19.

A.2. Kano Category for Initial Customer Requirements. See Table 20 .

A.3. Reserved Customer Requirements. See Table 21.

\section{B. Determination of the Weight of Customer Requirements Based on Interval 2-Tuple Linguistic Representation Model}

B.1. Expert Language Complementary Judgment Matrix. See Table 22.

\section{B.2. Interval 2-Tuple Linguistic Judgment Matrix}

\footnotetext{
$\left[\left[\left(s_{4}, 0\right),\left(s_{4}, 0\right)\right]\left[\left(s_{4}, 0\right),\left(s_{6}, 0\right)\right]\left[\left(s_{6}, 0\right),\left(s_{7}, 0\right)\right]\left[\left(s_{3}, 0\right),\left(s_{5}, 0\right)\right]\left[\left(s_{4}, 0\right),\left(s_{4}, 0\right)\right]\left[\left(s_{4}, 0\right),\left(s_{4}, 0\right)\right]\left[\left(s_{4}, 0\right),\left(s_{4}, 0\right)\right]\left[\left(s_{2}, 0\right),\left(s_{3}, 0\right)\right]\left[\left(s_{1}, 0\right),\left(s_{2}, 0\right)\right]\left[\left(s_{4}, 0\right),\left(s_{6}, 0\right)\right]\right]$ $\left[\left(s_{3}, 0\right),\left(s_{4}, 0\right)\right]\left[\left(s_{4}, 0\right),\left(s_{4}, 0\right)\right]\left[\left(s_{4}, 0\right),\left(s_{4}, 0\right)\right]\left[\left(s_{2}, 0\right),\left(s_{3}, 0\right)\right]\left[\left(s_{6}, 0\right),\left(s_{7}, 0\right)\right]\left[\left(s_{4}, 0\right),\left(s_{4}, 0\right)\right]\left[\left(s_{5}, 0\right),\left(s_{6}, 0\right)\right]\left[\left(s_{2}, 0\right),\left(s_{4}, 0\right)\right]\left[\left(s_{3}, 0\right),\left(s_{4}, 0\right)\right]\left[\left(s_{4}, 0\right),\left(s_{6}, 0\right)\right]$ $\left[\left(s_{4}, 0\right),\left(s_{4}, 0\right)\right]\left[\left(s_{5}, 0\right),\left(s_{6}, 0\right)\right]\left[\left(s_{4}, 0\right),\left(s_{4}, 0\right)\right]\left[\left(s_{6}, 0\right),\left(s_{7}, 0\right)\right]\left[\left(s_{6}, 0\right),\left(s_{7}, 0\right)\right]\left[\left(s_{6}, 0\right),\left(s_{7}, 0\right)\right]\left[\left(s_{5}, 0\right),\left(s_{6}, 0\right)\right]\left[\left(s_{6}, 0\right),\left(s_{7}, 0\right)\right]\left[\left(s_{4}, 0\right),\left(s_{4}, 0\right)\right]\left[\left(s_{2}, 0\right),\left(s_{3}, 0\right)\right]$ $\left[\left(s_{2}, 0\right),\left(s_{3}, 0\right)\right]\left[\left(s_{4}, 0\right),\left(s_{4}, 0\right)\right]\left[\left(s_{2}, 0\right),\left(s_{4}, 0\right)\right]\left[\left(s_{4}, 0\right),\left(s_{4}, 0\right)\right]\left[\left(s_{2}, 0\right),\left(s_{3}, 0\right)\right]\left[\left(s_{4}, 0\right),\left(s_{6}, 0\right)\right]\left[\left(s_{5}, 0\right),\left(s_{7}, 0\right)\right]\left[\left(s_{3}, 0\right),\left(s_{4}, 0\right)\right]\left[\left(s_{6}, 0\right),\left(s_{6}, 0\right)\right]\left[\left(s_{6}, 0\right),\left(s_{7}, 0\right)\right]$ $R 1=$ $\left[\left(s_{5}, 0\right),\left(s_{6}, 0\right)\right]\left[\left(s_{4}, 0\right),\left(s_{6}, 0\right)\right]\left[\left(s_{4}, 0\right),\left(s_{4}, 0\right)\right]\left[\left(s_{5}, 0\right),\left(s_{6}, 0\right)\right]\left[\left(s_{4}, 0\right),\left(s_{4}, 0\right)\right]\left[\left(s_{4}, 0\right),\left(s_{4}, 0\right)\right]\left[\left(s_{5}, 0\right),\left(s_{7}, 0\right)\right]\left[\left(s_{1}, 0\right),\left(s_{2}, 0\right)\right]\left[\left(s_{4}, 0\right),\left(s_{6}, 0\right)\right]\left[\left(s_{1}, 0\right),\left(s_{3}, 0\right)\right]$ $\left[\left(s_{2}, 0\right),\left(s_{2}, 0\right)\right]\left[\left(s_{6}, 0\right),\left(s_{7}, 0\right)\right]\left[\left(s_{4}, 0\right),\left(s_{6}, 0\right)\right]\left[\left(s_{1}, 0\right),\left(s_{3}, 0\right)\right]\left[\left(s_{5}, 0\right),\left(s_{6}, 0\right)\right]\left[\left(s_{4}, 0\right),\left(s_{4}, 0\right)\right]\left[\left(s_{4}, 0\right),\left(s_{4}, 0\right)\right]\left[\left(s_{5}, 0\right),\left(s_{6}, 0\right)\right]\left[\left(s_{6}, 0\right),\left(s_{7}, 0\right)\right]\left[\left(s_{5}, 0\right),\left(s_{6}, 0\right)\right]$ $\left[\left(s_{6}, 0\right),\left(s_{6}, 0\right)\right]\left[\left(s_{5}, 0\right),\left(s_{7}, 0\right)\right]\left[\left(s_{4}, 0\right),\left(s_{4}, 0\right)\right]\left[\left(s_{4}, 0\right),\left(s_{6}, 0\right)\right]\left[\left(s_{3}, 0\right),\left(s_{4}, 0\right)\right]\left[\left(s_{3}, 0\right),\left(s_{3}, 0\right)\right]\left[\left(s_{4}, 0\right),\left(s_{4}, 0\right)\right]\left[\left(s_{2}, 0\right),\left(s_{3}, 0\right)\right]\left[\left(s_{4}, 0\right),\left(s_{4}, 0\right)\right]\left[\left(s_{3}, 0\right),\left(s_{4}, 0\right)\right]$ $\left[\left(s_{6}, 0\right),\left(s_{7}, 0\right)\right]\left[\left(s_{5}, 0\right),\left(s_{7}, 0\right)\right]\left[\left(s_{6}, 0\right),\left(s_{6}, 0\right)\right]\left[\left(s_{5}, 0\right),\left(s_{7}, 0\right)\right]\left[\left(s_{2}, 0\right),\left(s_{3}, 0\right)\right]\left[\left(s_{6}, 0\right),\left(s_{6}, 0\right)\right]\left[\left(s_{5}, 0\right),\left(s_{7}, 0\right)\right]\left[\left(s_{4}, 0\right),\left(s_{4}, 0\right)\right]\left[\left(s_{4}, 0\right),\left(s_{4}, 0\right)\right]\left[\left(s_{4}, 0\right),\left(s_{6}, 0\right)\right]$ $\left[\left(s_{4}, 0\right),\left(s_{6}, 0\right)\right]\left[\left(s_{2}, 0\right),\left(s_{3}, 0\right)\right]\left[\left(s_{3}, 0\right),\left(s_{4}, 0\right)\right]\left[\left(s_{1}, 0\right),\left(s_{2}, 0\right)\right]\left[\left(s_{3}, 0\right),\left(s_{4}, 0\right)\right]\left[\left(s_{5}, 0\right),\left(s_{6}, 0\right)\right]\left[\left(s_{4}, 0\right),\left(s_{6}, 0\right)\right]\left[\left(s_{4}, 0\right),\left(s_{4}, 0\right)\right]\left[\left(s_{4}, 0\right),\left(s_{4}, 0\right)\right]\left[\left(s_{4}, 0\right),\left(s_{4}, 0\right)\right]$ $\left.\left[\left(s_{4}, 0\right),\left(s_{6}, 0\right)\right]\left[\left(s_{2}, 0\right),\left(s_{3}, 0\right)\right]\left[\left(s_{5}, 0\right),\left(s_{6}, 0\right)\right]\left[\left(s_{1}, 0\right),\left(s_{2}, 0\right)\right]\left[\left(s_{4}, 0\right),\left(s_{6}, 0\right)\right]\left[\left(s_{2}, 0\right),\left(s_{2}, 0\right)\right]\left[\left(s_{6}, 0\right),\left(s_{7}, 0\right)\right]\left[\left(s_{4}, 0\right),\left(s_{6}, 0\right)\right]\left[\left(s_{3}, 0\right),\left(s_{5}, 0\right)\right]\left[\left(s_{4}, 0\right),\left(s_{4}, 0\right)\right]\right]$

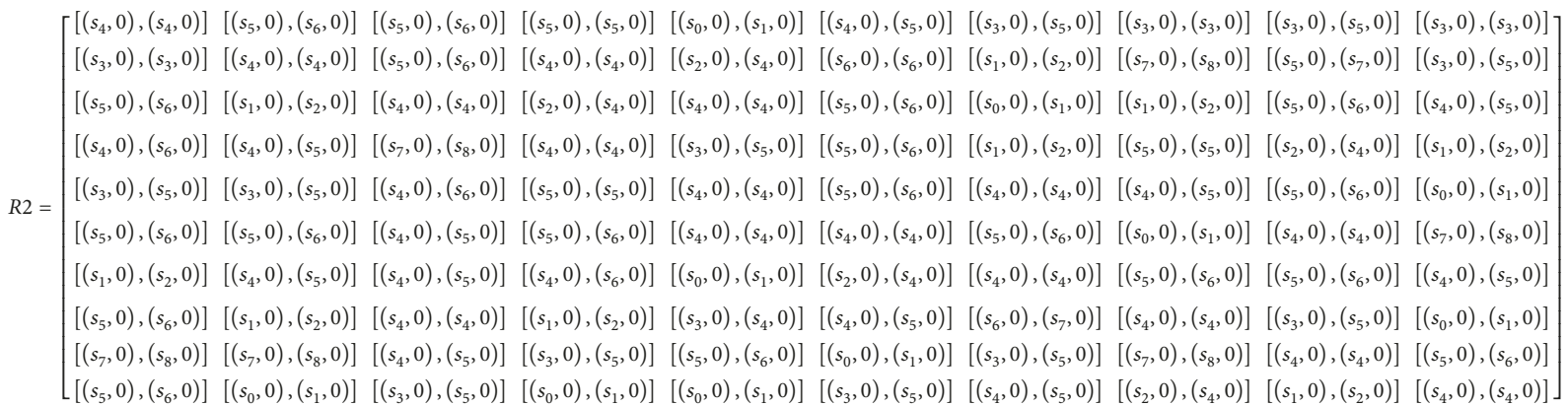


$R 3$

$\left[\left[\left(x_{3}, 0\right),\left(x_{3}, 0\right)\right]\left[\left(x_{4}, 0\right),\left(x_{5}, 0\right)\right]\left[\left(x_{1}, 0\right),\left(x_{2}, 0\right)\right]\left[\left(x_{4}, 0\right),\left(x_{5}, 0\right)\right]\left[\left(x_{1}, 0\right),\left(x_{2}, 0\right)\right]\left[\left(x_{3}, 0\right),\left(x_{4}, 0\right)\right]\left[\left(x_{0}, 0\right),\left(x_{1}, 0\right)\right]\left[\left(x_{1}, 0\right),\left(x_{2}, 0\right)\right]\left[\left(x_{2}, 0\right),\left(x_{4}, 0\right)\right]\left[\left(x_{2}, 0\right),\left(x_{4}, 0\right)\right]\right.$ $\left[\left(x_{4}, 0\right),\left(x_{5}, 0\right)\right]\left[\left(x_{3}, 0\right),\left(x_{3}, 0\right)\right]\left[\left(x_{3}, 0\right),\left(x_{3}, 0\right)\right]\left[\left(x_{1}, 0\right),\left(x_{2}, 0\right)\right]\left[\left(x_{4}, 0\right),\left(x_{5}, 0\right)\right]\left[\left(x_{0}, 0\right),\left(x_{1}, 0\right)\right]\left[\left(x_{0}, 0\right),\left(x_{1}, 0\right)\right]\left[\left(x_{0}, 0\right),\left(x_{1}, 0\right)\right]\left[\left(x_{4}, 0\right),\left(x_{5}, 0\right)\right]\left[\left(x_{1}, 0\right),\left(x_{2}, 0\right)\right]$ $\left[\left(x_{4}, 0\right),\left(x_{5}, 0\right)\right]\left[\left(x_{2}, 0\right),\left(x_{4}, 0\right)\right]\left[\left(x_{3}, 0\right),\left(x_{3}, 0\right)\right]\left[\left(x_{3}, 0\right),\left(x_{4}, 0\right)\right]\left[\left(x_{0}, 0\right),\left(x_{1}, 0\right)\right]\left[\left(x_{3}, 0\right),\left(x_{4}, 0\right)\right]\left[\left(x_{4}, 0\right),\left(x_{5}, 0\right)\right]\left[\left(x_{1}, 0\right),\left(x_{2}, 0\right)\right]\left[\left(x_{1}, 0\right),\left(x_{2}, 0\right)\right]\left[\left(x_{3}, 0\right),\left(x_{3}, 0\right)\right]$ $\left[\left(x_{2}, 0\right),\left(x_{4}, 0\right)\right]\left[\left(x_{3}, 0\right),\left(x_{4}, 0\right)\right]\left[\left(x_{1}, 0\right),\left(x_{2}, 0\right)\right]\left[\left(x_{3}, 0\right),\left(x_{3}, 0\right)\right]\left[\left(x_{2}, 0\right),\left(x_{4}, 0\right)\right]\left[\left(x_{0}, 0\right),\left(x_{1}, 0\right)\right]\left[\left(x_{2}, 0\right),\left(x_{4}, 0\right)\right]\left[\left(x_{1}, 0\right),\left(x_{3}, 0\right)\right]\left[\left(x_{1}, 0\right),\left(x_{2}, 0\right)\right]\left[\left(x_{2}, 0\right),\left(x_{4}, 0\right)\right]$ $\left[\left(x_{3}, 0\right),\left(x_{3}, 0\right)\right]\left[\left(x_{0}, 0\right),\left(x_{1}, 0\right)\right]\left[\left(x_{2}, 0\right),\left(x_{4}, 0\right)\right]\left[\left(x_{1}, 0\right),\left(x_{3}, 0\right)\right]\left[\left(x_{3}, 0\right),\left(x_{3}, 0\right)\right]\left[\left(x_{4}, 0\right),\left(x_{5}, 0\right)\right]\left[\left(x_{4}, 0\right),\left(x_{5}, 0\right)\right]\left[\left(x_{1}, 0\right),\left(x_{2}, 0\right)\right]\left[\left(x_{2}, 0\right),\left(x_{4}, 0\right)\right]\left[\left(x_{1}, 0\right),\left(x_{3}, 0\right)\right]$

$=\left[\left(x_{4}, 0\right),\left(x_{5}, 0\right)\right]\left[\left(x_{3}, 0\right),\left(x_{4}, 0\right)\right]\left[\left(x_{2}, 0\right),\left(x_{3}, 0\right)\right]\left[\left(x_{2}, 0\right),\left(x_{4}, 0\right)\right]\left[\left(x_{1}, 0\right),\left(x_{3}, 0\right)\right]\left[\left(x_{3}, 0\right),\left(x_{3}, 0\right)\right]\left[\left(x_{5}, 0\right),\left(x_{5}, 0\right)\right]\left[\left(x_{2}, 0\right),\left(x_{4}, 0\right)\right]\left[\left(x_{2}, 0\right),\left(x_{4}, 0\right)\right]\left[\left(x_{2}, 0\right),\left(x_{4}, 0\right)\right]$ $\left[\left(x_{4}, 0\right),\left(x_{5}, 0\right)\right]\left[\left(x_{2}, 0\right),\left(x_{4}, 0\right)\right]\left[\left(x_{2}, 0\right),\left(x_{4}, 0\right)\right]\left[\left(x_{2}, 0\right),\left(x_{4}, 0\right)\right]\left[\left(x_{2}, 0\right),\left(x_{3}, 0\right)\right]\left[\left(x_{3}, 0\right),\left(x_{4}, 0\right)\right]\left[\left(x_{3}, 0\right),\left(x_{3}, 0\right)\right]\left[\left(x_{3}, 0\right),\left(x_{4}, 0\right)\right]\left[\left(x_{4}, 0\right),\left(x_{5}, 0\right)\right]\left[\left(x_{3}, 0\right),\left(x_{4}, 0\right)\right]$ $\left[\left(x_{2}, 0\right),\left(x_{4}, 0\right)\right]\left[\left(x_{4}, 0\right),\left(x_{5}, 0\right)\right]\left[\left(x_{4}, 0\right),\left(x_{5}, 0\right)\right]\left[\left(x_{4}, 0\right),\left(x_{5}, 0\right)\right]\left[\left(x_{2}, 0\right),\left(x_{4}, 0\right)\right]\left[\left(x_{3}, 0\right),\left(x_{4}, 0\right)\right]\left[\left(x_{0}, 0\right),\left(x_{1}, 0\right)\right]\left[\left(x_{3}, 0\right),\left(x_{3}, 0\right)\right]\left[\left(x_{3}, 0\right),\left(x_{4}, 0\right)\right]\left[\left(x_{0}, 0\right),\left(x_{1}, 0\right)\right]$ $\left[\left(x_{0}, 0\right),\left(x_{1}, 0\right)\right]\left[\left(x_{3}, 0\right),\left(x_{3}, 0\right)\right]\left[\left(x_{2}, 0\right),\left(x_{4}, 0\right)\right]\left[\left(x_{3}, 0\right),\left(x_{3}, 0\right)\right]\left[\left(x_{1}, 0\right),\left(x_{2}, 0\right)\right]\left[\left(x_{4}, 0\right),\left(x_{5}, 0\right)\right]\left[\left(x_{2}, 0\right),\left(x_{4}, 0\right)\right]\left[\left(x_{4}, 0\right),\left(x_{5}, 0\right)\right]\left[\left(x_{3}, 0\right),\left(x_{3}, 0\right)\right]\left[\left(x_{1}, 0\right),\left(x_{2}, 0\right)\right]$

$\left[\left(\left(x_{2}, 0\right),\left(x_{4}, 0\right)\right]\left[\left(x_{4}, 0\right),\left(x_{5}, 0\right)\right]\left[\left(x_{3}, 0\right),\left(x_{4}, 0\right)\right]\left[\left(x_{4}, 0\right),\left(x_{5}, 0\right)\right]\left[\left(x_{2}, 0\right),\left(x_{4}, 0\right)\right]\left[\left(x_{0}, 0\right),\left(x_{1}, 0\right)\right]\left[\left(x_{2}, 0\right),\left(x_{4}, 0\right)\right]\left[\left(x_{2}, 0\right),\left(x_{4}, 0\right)\right]\left[\left(x_{1}, 0\right),\left(x_{2}, 0\right)\right]\left[\left(x_{3}, 0\right),\left(x_{3}, 0\right)\right]\right]$

$R 4$

$\left[\left[\left(x_{3}, 0\right),\left(x_{3}, 0\right)\right]\left[\left(x_{1}, 0\right),\left(x_{2}, 0\right)\right]\left[\left(x_{4}, 0\right),\left(x_{5}, 0\right)\right]\left[\left(x_{2}, 0\right),\left(x_{4}, 0\right)\right]\left[\left(x_{3}, 0\right),\left(x_{5}, 0\right)\right]\left[\left(x_{2}, 0\right),\left(x_{3}, 0\right)\right]\left[\left(x_{3}, 0\right),\left(x_{3}, 0\right)\right]\left[\left(x_{3}, 0\right),\left(x_{5}, 0\right)\right]\left[\left(x_{4}, 0\right),\left(x_{5}, 0\right)\right]\left[\left(x_{5}, 0\right),\left(x_{5}, 0\right)\right]\right]$ $\left[\left(x_{3}, 0\right),\left(x_{4}, 0\right)\right]\left[\left(x_{3}, 0\right),\left(x_{3}, 0\right)\right]\left[\left(x_{2}, 0\right),\left(x_{3}, 0\right)\right]\left[\left(x_{3}, 0\right),\left(x_{3}, 0\right)\right]\left[\left(x_{2}, 0\right),\left(x_{3}, 0\right)\right]\left[\left(x_{2}, 0\right),\left(x_{3}, 0\right)\right]\left[\left(x_{2}, 0\right),\left(x_{4}, 0\right)\right]\left[\left(x_{2}, 0\right),\left(x_{3}, 0\right)\right]\left[\left(x_{2}, 0\right),\left(x_{3}, 0\right)\right]\left[\left(x_{2}, 0\right),\left(x_{3}, 0\right)\right]$ $\left[\left(x_{2}, 0\right),\left(x_{4}, 0\right)\right]\left[\left(x_{3}, 0\right),\left(x_{3}, 0\right)\right]\left[\left(x_{3}, 0\right),\left(x_{3}, 0\right)\right]\left[\left(x_{4}, 0\right),\left(x_{5}, 0\right)\right]\left[\left(x_{2}, 0\right),\left(x_{3}, 0\right)\right]\left[\left(x_{5}, 0\right),\left(x_{5}, 0\right)\right]\left[\left(x_{4}, 0\right),\left(x_{5}, 0\right)\right]\left[\left(x_{2}, 0\right),\left(x_{3}, 0\right)\right]\left[\left(x_{3}, 0\right),\left(x_{4}, 0\right)\right]\left[\left(x_{4}, 0\right),\left(x_{5}, 0\right)\right]$ $\left[\left(x_{4}, 0\right),\left(x_{5}, 0\right)\right]\left[\left(x_{5}, 0\right),\left(x_{5}, 0\right)\right]\left[\left(x_{3}, 0\right),\left(x_{4}, 0\right)\right]\left[\left(x_{3}, 0\right),\left(x_{3}, 0\right)\right]\left[\left(x_{3}, 0\right),\left(x_{4}, 0\right)\right]\left[\left(x_{3}, 0\right),\left(x_{3}, 0\right)\right]\left[\left(x_{2}, 0\right),\left(x_{3}, 0\right)\right]\left[\left(x_{3}, 0\right),\left(x_{4}, 0\right)\right]\left[\left(x_{2}, 0\right),\left(x_{4}, 0\right)\right]\left[\left(x_{2}, 0\right),\left(x_{3}, 0\right)\right]$ $\left[\left(x_{2}, 0\right),\left(x_{3}, 0\right)\right]\left[\left(x_{2}, 0\right),\left(x_{3}, 0\right)\right]\left[\left(x_{4}, 0\right),\left(x_{5}, 0\right)\right]\left[\left(x_{2}, 0\right),\left(x_{3}, 0\right)\right]\left[\left(x_{3}, 0\right),\left(x_{3}, 0\right)\right]\left[\left(x_{3}, 0\right),\left(x_{3}, 0\right)\right]\left[\left(x_{2}, 0\right),\left(x_{3}, 0\right)\right]\left[\left(x_{2}, 0\right),\left(x_{3}, 0\right)\right]\left[\left(x_{4}, 0\right),\left(x_{5}, 0\right)\right]\left[\left(x_{3}, 0\right),\left(x_{4}, 0\right)\right]$

$=\left[\left(x_{4}, 0\right),\left(x_{5}, 0\right)\right]\left[\left(x_{2}, 0\right),\left(x_{4}, 0\right)\right]\left[\left(x_{2}, 0\right),\left(x_{3}, 0\right)\right]\left[\left(x_{2}, 0\right),\left(x_{3}, 0\right)\right]\left[\left(x_{2}, 0\right),\left(x_{3}, 0\right)\right]\left[\left(x_{3}, 0\right),\left(x_{3}, 0\right)\right]\left[\left(x_{3}, 0\right),\left(x_{3}, 0\right)\right]\left[\left(x_{3}, 0\right),\left(x_{3}, 0\right)\right]\left[\left(x_{3}, 0\right),\left(x_{4}, 0\right)\right]\left[\left(x_{2}, 0\right),\left(x_{3}, 0\right)\right]$ $\left[\left(x_{2}, 0\right),\left(x_{4}, 0\right)\right]\left[\left(x_{3}, 0\right),\left(x_{3}, 0\right)\right]\left[\left(x_{4}, 0\right),\left(x_{5}, 0\right)\right]\left[\left(x_{2}, 0\right),\left(x_{3}, 0\right)\right]\left[\left(x_{3}, 0\right),\left(x_{4}, 0\right)\right]\left[\left(x_{2}, 0\right),\left(x_{3}, 0\right)\right]\left[\left(x_{3}, 0\right),\left(x_{3}, 0\right)\right]\left[\left(x_{5}, 0\right),\left(x_{5}, 0\right)\right]\left[\left(x_{4}, 0\right),\left(x_{5}, 0\right)\right]\left[\left(x_{3}, 0\right),\left(x_{5}, 0\right)\right]$ $\left[\left(x_{3}, 0\right),\left(x_{3}, 0\right)\right]\left[\left(x_{2}, 0\right),\left(x_{3}, 0\right)\right]\left[\left(x_{3}, 0\right),\left(x_{3}, 0\right)\right]\left[\left(x_{2}, 0\right),\left(x_{3}, 0\right)\right]\left[\left(x_{2}, 0\right),\left(x_{3}, 0\right)\right]\left[\left(x_{2}, 0\right),\left(x_{3}, 0\right)\right]\left[\left(x_{3}, 0\right),\left(x_{5}, 0\right)\right]\left[\left(x_{3}, 0\right),\left(x_{3}, 0\right)\right]\left[\left(x_{2}, 0\right),\left(x_{4}, 0\right)\right]\left[\left(x_{3}, 0\right),\left(x_{3}, 0\right)\right]$ $\left[\left(x_{2}, 0\right),\left(x_{3}, 0\right)\right]\left[\left(x_{2}, 0\right),\left(x_{4}, 0\right)\right]\left[\left(x_{5}, 0\right),\left(x_{5}, 0\right)\right]\left[\left(x_{4}, 0\right),\left(x_{5}, 0\right)\right]\left[\left(x_{2}, 0\right),\left(x_{3}, 0\right)\right]\left[\left(x_{5}, 0\right),\left(x_{5}, 0\right)\right]\left[\left(x_{4}, 0\right),\left(x_{5}, 0\right)\right]\left[\left(x_{2}, 0\right),\left(x_{3}, 0\right)\right]\left[\left(x_{3}, 0\right),\left(x_{3}, 0\right)\right]\left[\left(x_{2}, 0\right),\left(x_{3}, 0\right)\right]$

$\left[\left(x_{3}, 0\right),\left(x_{3}, 0\right)\right]\left[\left(x_{2}, 0\right),\left(x_{3}, 0\right)\right]\left[\left(x_{3}, 0\right),\left(x_{3}, 0\right)\right]\left[\left(x_{2}, 0\right),\left(x_{4}, 0\right)\right]\left[\left(x_{3}, 0\right),\left(x_{5}, 0\right)\right]\left[\left(x_{3}, 0\right),\left(x_{3}, 0\right)\right]\left[\left(x_{3}, 0\right),\left(x_{3}, 0\right)\right]\left[\left(x_{3}, 0\right),\left(x_{3}, 0\right)\right]\left[\left(x_{2}, 0\right),\left(x_{3}, 0\right)\right]\left[\left(x_{3}, 0\right),\left(x_{3}, 0\right)\right]$

R5

$\left[\left[\left(y_{2}, 0\right),\left(y_{2}, 0\right)\right]\left[\left(y_{2}, 0\right),\left(y_{4}, 0\right)\right]\left[\left(y_{2}, 0\right),\left(y_{3}, 0\right)\right]\left[\left(y_{2}, 0\right),\left(y_{3}, 0\right)\right]\left[\left(y_{2}, 0\right),\left(y_{3}, 0\right)\right]\left[\left(y_{0}, 0\right),\left(y_{2}, 0\right)\right]\left[\left(y_{0}, 0\right),\left(y_{1}, 0\right)\right]\left[\left(y_{2}, 0\right),\left(y_{3}, 0\right)\right]\left[\left(y_{1}, 0\right),\left(y_{3}, 0\right)\right]\left[\left(y_{2}, 0\right),\left(y_{4}, 0\right)\right]\right]$ $\left[\left(y_{0}, 0\right),\left(y_{1}, 0\right)\right]\left[\left(y_{2}, 0\right),\left(y_{2}, 0\right)\right]\left[\left(y_{0}, 0\right),\left(y_{1}, 0\right)\right]\left[\left(y_{2}, 0\right),\left(y_{4}, 0\right)\right]\left[\left(y_{3}, 0\right),\left(y_{4}, 0\right)\right]\left[\left(y_{1}, 0\right),\left(y_{3}, 0\right)\right]\left[\left(y_{0}, 0\right),\left(y_{2}, 0\right)\right]\left[\left(y_{1}, 0\right),\left(y_{3}, 0\right)\right]\left[\left(y_{2}, 0\right),\left(y_{3}, 0\right)\right]\left[\left(y_{2}, 0\right),\left(y_{3}, 0\right)\right]$ $\left[\left(y_{1}, 0\right),\left(y_{3}, 0\right)\right]\left[\left(y_{1}, 0\right),\left(y_{3}, 0\right)\right]\left[\left(y_{2}, 0\right),\left(y_{2}, 0\right)\right]\left[\left(y_{0}, 0\right),\left(y_{2}, 0\right)\right]\left[\left(y_{2}, 0\right),\left(y_{3}, 0\right)\right]\left[\left(y_{4}, 0\right),\left(y_{4}, 0\right)\right]\left[\left(y_{2}, 0\right),\left(y_{4}, 0\right)\right]\left[\left(y_{2}, 0\right),\left(y_{3}, 0\right)\right]\left[\left(y_{2}, 0\right),\left(y_{4}, 0\right)\right]\left[\left(y_{0}, 0\right),\left(y_{1}, 0\right)\right]$ $\left[\left(y_{2}, 0\right),\left(y_{4}, 0\right)\right]\left[\left(y_{2}, 0\right),\left(y_{4}, 0\right)\right]\left[\left(y_{3}, 0\right),\left(y_{4}, 0\right)\right]\left[\left(y_{2}, 0\right),\left(y_{2}, 0\right)\right]\left[\left(y_{0}, 0\right),\left(y_{1}, 0\right)\right]\left[\left(y_{2}, 0\right),\left(y_{3}, 0\right)\right]\left[\left(y_{2}, 0\right),\left(y_{3}, 0\right)\right]\left[\left(y_{0}, 0\right),\left(y_{1}, 0\right)\right]\left[\left(y_{3}, 0\right),\left(y_{4}, 0\right)\right]\left[\left(y_{2}, 0\right),\left(y_{3}, 0\right)\right]$ $\left[\left(y_{1}, 0\right),\left(y_{3}, 0\right)\right]\left[\left(y_{2}, 0\right),\left(y_{3}, 0\right)\right]\left[\left(y_{1}, 0\right),\left(y_{3}, 0\right)\right]\left[\left(y_{1}, 0\right),\left(y_{3}, 0\right)\right]\left[\left(y_{2}, 0\right),\left(y_{2}, 0\right)\right]\left[\left(y_{3}, 0\right),\left(y_{4}, 0\right)\right]\left[\left(y_{4}, 0\right),\left(y_{4}, 0\right)\right]\left[\left(y_{2}, 0\right),\left(y_{3}, 0\right)\right]\left[\left(y_{1}, 0\right),\left(y_{3}, 0\right)\right]\left[\left(y_{2}, 0\right),\left(y_{4}, 0\right)\right]$ $\left[\left(y_{2}, 0\right),\left(y_{4}, 0\right)\right]\left[\left(y_{2}, 0\right),\left(y_{4}, 0\right)\right]\left[\left(y_{0}, 0\right),\left(y_{2}, 0\right)\right]\left[\left(y_{0}, 0\right),\left(y_{2}, 0\right)\right]\left[\left(y_{2}, 0\right),\left(y_{3}, 0\right)\right]\left[\left(y_{2}, 0\right),\left(y_{2}, 0\right)\right]\left[\left(y_{2}, 0\right),\left(y_{3}, 0\right)\right]\left[\left(y_{0}, 0\right),\left(y_{1}, 0\right)\right]\left[\left(y_{2}, 0\right),\left(y_{4}, 0\right)\right]\left[\left(y_{2}, 0\right),\left(y_{3}, 0\right)\right]$ $\left[\left(y_{0}, 0\right),\left(y_{2}, 0\right)\right]\left[\left(y_{2}, 0\right),\left(y_{4}, 0\right)\right]\left[\left(y_{2}, 0\right),\left(y_{4}, 0\right)\right]\left[\left(y_{2}, 0\right),\left(y_{4}, 0\right)\right]\left[\left(y_{1}, 0\right),\left(y_{3}, 0\right)\right]\left[\left(y_{0}, 0\right),\left(y_{2}, 0\right)\right]\left[\left(y_{2}, 0\right),\left(y_{2}, 0\right)\right]\left[\left(y_{0}, 0\right),\left(y_{2}, 0\right)\right]\left[\left(y_{1}, 0\right),\left(y_{3}, 0\right)\right]\left[\left(y_{3}, 0\right),\left(y_{4}, 0\right)\right]$ $\left[\left(y_{2}, 0\right),\left(y_{4}, 0\right)\right]\left[\left(y_{2}, 0\right),\left(y_{4}, 0\right)\right]\left[\left(y_{2}, 0\right),\left(y_{3}, 0\right)\right]\left[\left(y_{1}, 0\right),\left(y_{3}, 0\right)\right]\left[\left(y_{2}, 0\right),\left(y_{3}, 0\right)\right]\left[\left(y_{2}, 0\right),\left(y_{3}, 0\right)\right]\left[\left(y_{1}, 0\right),\left(y_{3}, 0\right)\right]\left[\left(y_{2}, 0\right),\left(y_{2}, 0\right)\right]\left[\left(y_{4}, 0\right),\left(y_{4}, 0\right)\right]\left[\left(y_{0}, 0\right),\left(y_{1}, 0\right)\right]$ $\left[\left(y_{2}, 0\right),\left(y_{3}, 0\right)\right]\left[\left(y_{1}, 0\right),\left(y_{3}, 0\right)\right]\left[\left(y_{3}, 0\right),\left(y_{4}, 0\right)\right]\left[\left(y_{2}, 0\right),\left(y_{4}, 0\right)\right]\left[\left(y_{2}, 0\right),\left(y_{4}, 0\right)\right]\left[\left(y_{2}, 0\right),\left(y_{3}, 0\right)\right]\left[\left(y_{1}, 0\right),\left(y_{3}, 0\right)\right]\left[\left(y_{0}, 0\right),\left(y_{2}, 0\right)\right]\left[\left(y_{2}, 0\right),\left(y_{2}, 0\right)\right]\left[\left(y_{1}, 0\right),\left(y_{3}, 0\right)\right]$ $\left[\left(\left(y_{3}, 0\right),\left(y_{4}, 0\right)\right]\left[\left(y_{2}, 0\right),\left(y_{3}, 0\right)\right]\left[\left(y_{0}, 0\right),\left(y_{2}, 0\right)\right]\left[\left(y_{3}, 0\right),\left(y_{4}, 0\right)\right]\left[\left(y_{2}, 0\right),\left(y_{3}, 0\right)\right]\left[\left(y_{2}, 0\right),\left(y_{4}, 0\right)\right]\left[\left(y_{2}, 0\right),\left(y_{3}, 0\right)\right]\left[\left(y_{2}, 0\right),\left(y_{4}, 0\right)\right]\left[\left(y_{2}, 0\right),\left(y_{3}, 0\right)\right]\left[\left(y_{2}, 0\right),\left(y_{2}, 0\right)\right]\right]$

\section{B.3. Interval Matrix}

$R^{1 \prime}$

$[0.500,0.500][0.500,0.750][0.750,0.875][0.375,0.625][0.500,0.500][0.500,0.500][0.500,0.500][0.250,0.375][0.125,0.250][0.500,0.750]]$ $[0.375,0.500][0.500,0.500][0.500,0.500][0.250,0.375][0.750,0.875][0.500,0.500][0.625,0.750][0.250,0.500][0.375,0.500][0.500,0.750]$ $[0.500,0.500][0.625,0.750][0.500,0.500][0.750,0.875][0.750,0.875][0.625,0.750][0.750,0.875][0.750,0.875][0.500,0.500][0.250,0.375]$ $[0.250,0.375][0.500,0.500][0.250,0.500][0.500,0.500][0.250,0.375][0.500,0.750][0.625,0.875][0.375,0.500][0.750,0.750][0.750,0.875]$ $[0.625,0.750][0.500,0.750][0.500,0.500][0.625,0.750][0.500,0.500][0.500,0.500][0.625,0.875][0.125,0.250][0.500,0.750][0.125,0.375]$ $=$ $[0.250,0.250][0.750,0.875][0.500,0.750][0.125,0.375][0.625,0.750][0.500,0.500][0.500,0.500][0.625,0.750][0.750,0.875][0.625,0.750]$ $[0.750,0.750][0.625,0.875][0.500,0.500][0.500,0.750][0.375,0.500][0.375,0.375][0.500,0.500][0.250,0.375][0.500,0.500][0.375,0.500]$ $[0.750,0.875][0.625,0.875][0.750,0.750][0.625,0.875][0.250,0.375][0.750,0.750][0.625,0.875][0.500,0.500][0.500,0.500][0.500,0.750]$ $[0.500,0.750][0.250,0.375][0.375,0.500][0.125,0.250][0.375,0.500][0.625,0.750][0.500,0.750][0.500,0.500][0.500,0.500][0.500,0.500]$ $[0.500,0.750][0.250,0.375][0.625,0.750][0.125,0.250][0.500,0.750][0.250,0.250][0.750,0.875][0.500,0.750][0.375,0.625][0.500,0.500]$

$R^{2 \prime}$

$[[0.500,0.500][0.625,0.750][0.625,0.750][0.625,0.625][0.000,0.125][0.500,0.625][0.375,0.625][0.375,0.375][0.375,0.625][0.375,0.375]$ $[0.375,0.375][0.500,0.500][0.625,0.750][0.500,0.500][0.250,0.500][0.750,0.750][0.125,0.250][0.875,1.000][0.625,0.875][0.375,0.625]$ $[0.625,0.750][0.125,0.250][0.500,0.500][0.250,0.500][0.500,0.500][0.625,0.750][0.000,0.125][0.125,0.250][0.625,0.750][0.500,0.625]$ $[0.500,0.750][0.500,0.625][0.875,1.000][0.500,0.500][0.375,0.625][0.625,0.750][0.125,0.250][0.625,0.625][0.250,0.500][0.125,0.250]$ $[0.375,0.625][0.375,0.625][0.500,0.750][0.625,0.625][0.500,0.500][0.625,0.750][0.500,0.500][0.500,0.625][0.625,0.750][0.000,0.125]$ $[0.625,0.750][0.625,0.750][0.500,0.625][0.625,0.750][0.500,0.500][0.500,0.500][0.625,0.750][0.000,0.125][0.500,0.500][0.875,1.000]$ $[0.125,0.250][0.500,0.625][0.500,0.625][0.500,0.750][0.000,0.125][0.250,0.500][0.500,0.500][0.625,0.750][0.625,0.750][0.500,0.625]$ $[0.625,0.750][0.125,0.250][0.500,0.500][0.125,0.250][0.375,0.500][0.500,0.625][0.750,0.875][0.500,0.500][0.375,0.625][0.000,0.125]$ $[0.875,1.000][0.875,1.000][0.500,0.625][0.375,0.625][0.625,0.750][0.000,0.125][0.375,0.625][0.875,1.000][0.500,0.500][0.625,0.750]$ $[0.625,0.750][0.000,0.125][0.375,0.625][0.000,0.125][0.000,0.125][0.375,0.625][0.500,0.625][0.250,0.500][0.125,0.250][0.500,0.500]]$ 
$R^{31}$

$[[0.500,0.500][0.667,0.833][0.167,0.333][0.667,0.833][0.167,0.333][0.500,0.667][0.000,0.167][0.167,0.333][0.333,0.667][0.333,0.667]$ $[0.667,0.833][0.500,0.500][0.500,0.500][0.167,0.333][0.667,0.833][0.000,0.167][0.000,0.167][0.000,0.167][0.667,0.833][0.167,0.333]$ $[0.667,0.833][0.333,0.667][0.500,0.500][0.500,0.667][0.000,0.167][0.500,0.667][0.667,0.833][0.167,0.333][0.167,0.333][0.500,0.500]$ $[0.333,0.667][0.500,0.667][0.167,0.333][0.500,0.500][0.333,0.667][0.000,0.167][0.333,0.667][0.167,0.500][0.167,0.333][0.333,0.667]$ $[0.500,0.500][0.000,0.167][0.333,0.667][0.167,0.500][0.500,0.500][0.667,0.833][0.667,0.833][0.167,0.333][0.333,0.667][0.167,0.500]$ $[0.667,0.833][0.500,0.667][0.333,0.500][0.333,0.667][0.167,0.500][0.500,0.500][0.833,0.833][0.333,0.667][0.333,0.667][0.333,0.667]$ $[0.667,0.833][0.333,0.667][0.333,0.667][0.333,0.667][0.333,0.500][0.500,0.667][0.500,0.500][0.500,0.667][0.667,0.833][0.500,0.667]$ $[0.333,0.667][0.667,0.833][0.667,0.833][0.667,0.833][0.333,0.667][0.500,0.667][0.000,0.167][0.500,0.500] \quad[0.500,0.667][0.000,0.167]$ $[0.000,0.167][0.500,0.500][0.333,0.667][0.500,0.500][0.167,0.333][0.667,0.833][0.333,0.667][0.667,0.833][0.500,0.500][0.167,0.333]$ $\left[\begin{array}{lll}{[0.333,0.667]} & {[0.667,0.833][0.500,0.667][0.667,0.833][0.333,0.667][0.000,0.167][0.333,0.667]} & {[0.333,0.667][0.167,0.333][0.500,0.500]}\end{array}\right.$ $R^{4 \prime}$

$[0.500,0.500][0.167,0.333][0.667,0.833][0.333,0.667][0.500,0.833][0.333,0.500][0.500,0.500][0.500,0.833] \quad[0.667,0.833][0.833,0.833]$ $[0.500,0.667][0.500,0.500][0.333,0.500][0.500,0.500][0.333,0.500][0.333,0.500][0.333,0.667][0.333,0.500][0.333,0.500][0.333,0.500]$ $[0.333,0.667][0.500,0.500][0.500,0.500][0.667,0.833][0.333,0.500][0.833,0.833][0.667,0.833][0.333,0.500][0.500,0.667][0.667,0.833]$ $[0.667,0.833][0.833,0.833][0.500,0.667][0.500,0.500][0.500,0.667][0.500,0.500][0.333,0.500][0.500,0.667][0.333,0.667][0.333,0.500]$ $[0.333,0.500][0.333,0.500][0.667,0.833][0.333,0.500][0.500,0.500][0.500,0.500][0.333,0.500][0.333,0.500][0.667,0.833][0.500,0.667]$ $[0.667,0.833][0.333,0.667][0.333,0.500][0.333,0.500][0.333,0.500][0.500,0.500][0.500,0.500][0.500,0.500][0.500,0.667][0.333,0.500]$ $[0.333,0.667][0.500,0.500][0.667,0.833][0.333,0.500][0.500,0.667][0.333,0.500][0.500,0.500][0.833,0.833][0.667,0.833][0.500,0.833]$ $[0.500,0.500][0.333,0.500][0.500,0.500][0.333,0.500][0.333,0.500][0.333,0.500][0.500,0.833][0.500,0.500][0.333,0.667][0.500,0.500]$ $[0.333,0.500][0.333,0.667][0.833,0.833][0.667,0.833][0.333,0.500][0.833,0.833][0.667,0.833][0.333,0.500] \quad[0.500,0.500][0.333,0.500]$ $[0.500,0.500][0.333,0.500][0.500,0.500][0.333,0.667][0.500,0.833][0.500,0.500][0.500,0.500][0.500,0.500][0.333,0.500][0.500,0.500]]$ $R^{5 \prime}$

$[0.500,0.500][0.500,1.000][0.500,0.750][0.500,0.750][0.500,0.750][0.000,0.500][0.000,0.250] \quad[0.500,0.750] \quad[0.250,0.750][0.500,1.000]]$ $[0.250,0.250][0.500,0.500][0.000,0.250][0.500,1.000][0.750,1.000][0.250,0.750][0.000,0.500] \quad[0.250,0.750][0.500,0.750][0.500,0.750]$ $[0.250,0.750][0.250,0.750][0.500,0.500][0.000,0.500][0.500,0.750][1.000,1.000][0.500,1.000][0.500,0.750][0.500,1.000][0.000,0.250]$ $[0.500,1.000][0.500,1.000][0.750,1.000][0.500,0.500][0.000,0.250][0.500,0.750][0.500,0.750] \quad[0.000,0.250][0.750,1.000][0.500,0.750]$ $[0.250,0.750][0.500,0.750][0.250,0.750][0.250,0.750][0.500,0.500][0.750,1.000][1.000,1.000][0.500,0.750][0.250,0.750][0.500,1.000]$ $[0.500,1.000][0.500,1.000][0.000,0.500][0.000,0.500][0.500,0.750][0.500,0.500][0.500,0.750][0.000,0.250] \quad[0.500,1.000][0.500,0.750]$ $[0.000,0.500][0.500,1.000][0.500,1.000][0.500,1.000][0.250,0.750][0.000,0.500][0.500,0.500] \quad[0.000,0.500][0.250,0.750][0.750,1.000]$ $[0.500,1.000][0.500,1.000][0.500,0.750][0.250,0.750][0.500,0.750][0.500,0.750][0.250,0.750] \quad[0.500,0.500] \quad[1.000,1.000] \quad[0.000,0.250]$ $[0.500,0.750][0.250,0.750][0.750,1.000][0.500,1.000][0.500,1.000][0.500,0.750][0.250,0.750][0.000,0.500][0.500,0.500][0.250,0.750]$ $[0.750,1.000][0.500,0.750][0.000,0.500][0.750,1.000][0.500,0.750][0.500,1.000][0.500,0.750][0.500,1.000][0.500,0.750][0.500,0.500]]$

\section{B.4. Interval 2-Tuple Linguistic Comprehensive Evaluation Matrix}

$\left[\begin{array}{lllllllllll}(0.500,0.500) & (0.498,0.708) & (0.561,0.714) & (0.500,0.688) & (0.308,0.464) & (0.417,0.565) & (0.319,0.440) & (0.340,0.496) & (0.350,0.594) & (0.502,0.681)\end{array}\right]$ $\begin{array}{llllllllllll}(0.500,0.544) & (0.500,0.500) & (0.448,0.538) & (0.371,0.485) & (0.525,0.710) & (0.404,0.521) & (0.254,0.469) & (0.373,0.583) & (0.500,0.685) & (0.369,0.585)\end{array}$ $\begin{array}{lllllllllll}(0.500,0.688) & (0.379,0.558) & (0.500,0.500) & (0.483,0.694) & (0.429,0.552) & (0.679,0.775) & (0.504,0.683) & (0.369,0.523) & (0.465,0.613) & (0.421,0.542)\end{array}$ $\begin{array}{lllllllllll}(0.500,0.681) & (0.567,0.681) & (0.490,0.675) & (0.500,0.500) & (0.323,0.542) & (0.431,0.583) & (0.371,0.590) & (0.383,0.540) & (0.425,0.613) & (0.402,0.590)\end{array}$ $\begin{array}{lllllllllll}(0.500,0.619) & (0.335,0.552 & (0.475,0.688) & (0.438,0.619) & (0.500,0.500) & (0.590,0.679) & (0.581,0.710) & (0.306,0.460) & (0.506,0.750) & (0.215,0.458)\end{array}$ $\begin{array}{lllllllllll}0.500,0.683) & (0.560,0.773) & (0.383,0.594) & (0.321,0.565) & (0.431,0.588) & (0.500,0.500) & (0.598,0.654) & (0.323,0.477) & (0.529,0.711) & (0.558,0.746)\end{array}$ $\begin{array}{lllllllllll}(0.500,0.600) & (0.498,0.708) & (0.500,0.681) & (0.433,0.708) & (0.285,0.465) & (0.323,0.502) & (0.500,0.500) & (0.485,0.631) & (0.573,0.721) & (0.494,0.681)\end{array}$ $\begin{array}{llllllllllll}(0.500,0.740) & (0.436,0.648) & (0.596,0.654) & (0.413,0.623) & (0.339,0.527) & (0.529,0.652) & (0.469,0.713) & (0.500,0.500) & (0.485,0.648) & (0.225,0.377)\end{array}$ $\begin{array}{lllllllllll}(0.500,0.646) & (0.473,0.652) & (0.527,0.681) & (0.408,0.585 & (0.400,0.579) & (0.506,0.627) & (0.444,0.719) & (0.544,0.692) & (0.500,0.500) & (0.406,0.554)\end{array}$ $\left[\begin{array}{llllllllll}(0.500,0.708) & (0.313,0.467) & (0.450,0.627) & (0.307,0.494) & (0.342,0.594) & (0.306,0.452) & (0.529,0.683) & (0.404,0.646) & (0.275,0.460) & (0.500,0.500)\end{array}\right]$ 
B.5. Weight Dependence and Possibility Matrix and Customer Demand Weights Based on Interval 2-Tuple Linguistic of Importance Evaluation Value $\boldsymbol{\theta}_{\boldsymbol{i}}$ $\theta_{i}$

$=\left[\begin{array}{llllll}(0.430,0.554) & (0.419,0.535) & (0.474,0.600) & (0.427,0.559) & (0.439,0.582)\end{array}\right.$

$P=\left[\begin{array}{llllllllll}0.500 & 0.563 & 0.320 & 0.496 & 0.431 & 0.331 & 0.401 & 0.414 & 0.352 & 0.639 \\ 0.438 & 0.500 & 0.252 & 0.436 & 0.371 & 0.261 & 0.337 & 0.353 & 0.285 & 0.581 \\ 0.680 & 0.748 & 0.500 & 0.671 & 0.599 & 0.516 & 0.575 & 0.585 & 0.534 & 0.817 \\ 0.504 & 0.565 & 0.330 & 0.500 & 0.436 & 0.340 & 0.408 & 0.421 & 0.361 & 0.638 \\ 0.569 & 0.629 & 0.402 & 0.564 & 0.500 & 0.414 & 0.475 & 0.486 & 0.432 & 0.698 \\ 0.669 & 0.739 & 0.484 & 0.660 & 0.586 & 0.500 & 0.562 & 0.572 & 0.519 & 0.811 \\ 0.599 & 0.663 & 0.425 & 0.593 & 0.525 & 0.438 & 0.500 & 0.511 & 0.457 & 0.733 \\ 0.586 & 0.647 & 0.415 & 0.579 & 0.514 & 0.428 & 0.489 & 0.500 & 0.447 & 0.716 \\ 0.648 & 0.716 & 0.466 & 0.639 & 0.568 & 0.481 & 0.543 & 0.553 & 0.500 & 0.786 \\ 0.361 & 0.419 & 0.183 & 0.362 & 0.302 & 0.189 & 0.267 & 0.284 & 0.214 & 0.500\end{array}\right]$

$\varphi=(0.094,0.087,0.114,0.095,0.102,0.112,0.105,0.104,0.110,0.079)$

\section{Data Availability}

All relevant data are within the paper.

\section{Conflicts of Interest}

The authors declare no conflicts of interest.

\section{Acknowledgments}

The study was supported by "Research Fund from Key Laboratory of Computer Integrated Manufacturing in Guangdong Province" (CIMSOF2016002), "State Key Laboratory for Manufacturing Systems Engineering (Xian Jiaotong University)" (sklms2017005), "Central University Science Research Foundation of China" (JB170609), "China Postdoctoral Science Foundation Funded Project" (2016M590929), and "Shaanxi Natural Science Foundation Project” (2017JM7004).

\section{References}

[1] P. Liu and P. Wang, "Some q-Rung Orthopair Fuzzy Aggregation Operators and their Applications to Multiple-Attribute Decision Making," International Journal of Intelligent Systems, vol. 33, no. 2, pp. 259-280, 2018.

[2] N. Franke and E. Von Hippel, "Satisfying heterogeneous user needs via innovation toolkits: the case of Apache security software," Research Policy, vol. 32, no. 7, pp. 1199-1215, 2003.

[3] G. L. Lilien, P. D. Morrison, K. Searls, M. Sonnack, and E. Von Hippel, "Performance assessment of the lead user ideageneration process for new product development," Management Science, vol. 48, no. 8, pp. 1042-1059, 2002.
[4] W. Song, X. Ming, Y. Han, and Z. Wu, "A rough set approach for evaluating vague customer requirement of industrial productservice system," International Journal of Production Research, vol. 51, no. 22, pp. 6681-6701, 2013.

[5] D. W. Dahl, C. Fuchs, and M. Schreier, "Why and when consumers prefer products of user-driven firms: A social identification account," Management Science, vol. 61, no. 8, pp. 1978-1988, 2015.

[6] X. Chen, C.-H. Chen, K. F. Leong, and X. Jiang, "An ontology learning system for customer needs representation in product development," The International Journal of Advanced Manufacturing Technology, vol. 67, no. 1-4, pp. 441-453, 2013.

[7] Y. Wang and M. M. Tseng, "Integrating comprehensive customer requirements into product design," CIRP Annals - Manufacturing Technology, vol. 60, no. 1, pp. 175-178, 2011.

[8] Y. Wang and M. Tseng, "Incorporating tolerances of customers' requirements for customized products," CIRP Annals - Manufacturing Technology, vol. 63, no. 1, pp. 129-132, 2014.

[9] Z. L. Liu, Z. Zhang, and Y. Chen, "A scenario-based approach for requirements management in engineering design," Concurrent Engineering Research Applications, vol. 20, no. 2, pp. 99-109, 2012.

[10] M. G. Violante, E. Vezzetti, and M. Alemanni, "An integrated approach to support the Requirement Management (RM) tool customization for a collaborative scenario," International Journal on Interactive Design and Manufacturing, vol. 11, no. 2, pp. 191-204, 2017.

[11] Z. Sheng, Y. Wang, J. Song, and H. Xie, "Customer requirement modeling and mapping of numerical control machine," Advances in Mechanical Engineering, vol. 7, no. 10, pp. 1-11, 2015.

[12] M. Carulli, M. Bordegoni, and U. Cugini, "An approach for capturing the Voice of the Customer based on Virtual Prototyping," Journal of Intelligent Manufacturing, vol. 24, no. 5, pp. 887-903, 2013.

[13] C. K. Kwong and H. Bai, "A fuzzy AHP approach to the determination of importance weights of customer requirements 
in quality function deployment," Journal of Intelligent Manufacturing, vol. 13, no. 5, pp. 367-377, 2002.

[14] H. M. Khalid and M. G. Helander, "A framework for affective customer needs in product design," Theoretical Issues in Ergonomics Science, vol. 5, no. 1, pp. 27-42, 2004.

[15] Y.-L. Li, K.-S. Chin, and X.-G. Luo, "Determining the final priority ratings of customer requirements in product planning by MDBM and BSC," Expert Systems with Applications, vol. 39, no. 1, pp. 1243-1255, 2012.

[16] Y. Wang and M. M. Tseng, "A Naïve Bayes approach to map customer requirements to product variants," Journal of Intelligent Manufacturing, vol. 26, no. 3, pp. 501-509, 2015.

[17] C. C. Aguwa, L. Monplaisir, and O. Turgut, "Voice of the customer: Customer satisfaction ratio based analysis," Expert Systems with Applications, vol. 39, no. 11, pp. 10112-10119, 2012.

[18] P. Liu, J. Liu, and J. M. Merigó, "Partitioned Heronian means based on linguistic intuitionistic fuzzy numbers for dealing with multi-attribute group decision making," Applied Soft Computing, vol. 62, pp. 395-422, 2018.

[19] Y.-E. Nahm, H. Ishikawa, and M. Inoue, "New rating methods to prioritize customer requirements in QFD with incomplete customer preferences," The International Journal of Advanced Manufacturing Technology, vol. 65, no. 9-12, pp. 1587-1604, 2013.

[20] H.-H. Wu, A. Y. H. Liao, and P.-C. Wang, "Using grey theory in quality function deployment to analyse dynamic customer requirements," The International Journal of Advanced Manufacturing Technology, vol. 25, no. 11-12, pp. 1241-1247, 2005.

[21] X. Liu, W. J. Zhang, Y. L. Tu, and R. Jiang, "An analytical approach to customer requirement satisfaction in design specification development," IEEE Transactions on Engineering Management, vol. 55, no. 1, pp. 94-102, 2008.

[22] S. Takai and K. Ishii, "A use of subjective clustering to support affinity diagram results in customer needs analysis," Concurrent Engineering Research and Applications, vol. 18, no. 2, pp. 101-109, 2010.

[23] P. Liu, J. Liu, and S.-M. Chen, "Some intuitionistic fuzzy Dombi Bonferroni mean operators and their application to multiattribute group decision making," Journal of the Operational Research Society, 2017.

[24] P. Liu and S.-M. Chen, "Group Decision Making Based on Heronian Aggregation Operators of Intuitionistic Fuzzy Numbers," IEEE Transactions on Cybernetics, 2016.

[25] Y. Dong, G. Zhang, W.-C. Hong, and S. Yu, "Linguistic computational model based on 2-tuples and intervals," IEEE Transactions on Fuzzy Systems, vol. 21, no. 6, pp. 1006-1018, 2013.

[26] F. Herrera and L. Martínez, "A 2-tuple fuzzy linguistic representation model for computing with words," IEEE Transactions on Fuzzy Systems, vol. 8, no. 6, pp. 746-752, 2000.

[27] F. Herrera and L. Martínez, "A model based on linguistic 2tuples for dealing with multigranular hierarchical linguistic contexts in multi-expert decision-making," IEEE Transactions on Systems, Man, and Cybernetics, Part B: Cybernetics, vol. 31, no. 2, pp. 227-234, 2001.

[28] C.-C. Li, Y. Dong, F. Herrera, E. Herrera-Viedma, and L. Martínez, "Personalized individual semantics in computing with words for supporting linguistic group decision making. An application on consensus reaching," Information Fusion, vol. 33, pp. 29-40, 2017.

[29] C. Li, R. M. Rodríguez, L. Martínez, Y. Dong, and F. Herrera, "Personalized individual semantics based on consistency in hesitant linguistic group decision making with comparative linguistic expressions," Knowledge-Based Systems, vol. 145, pp. 156-165, 2018.

[30] Y. Dong, C.-C. Li, and F. Herrera, "Connecting the linguistic hierarchy and the numerical scale for the 2-tuple linguistic model and its use to deal with hesitant unbalanced linguistic information," Information Sciences, vol. 367-368, pp. 259-278, 2016.

[31] X. Chen, H. Zhang, and Y. Dong, "The fusion process with heterogeneous preference structures in group decision making: a survey," Information Fusion, vol. 24, pp. 72-83, 2015.

[32] Y. Dong, H. Zhang, and E. Herrera-Viedma, "Consensus reaching model in the complex and dynamic MAGDM problem," Knowledge-Based Systems, vol. 106, pp. 206-219, 2016.

[33] P. D. Liu, "Multiple attribute group decision making method based on interval-valued intuitionistic fuzzy power heronian aggregation operators," Computers \& Industrial Engineering, vol. 108, pp. 199-212, 2017.

[34] P. Liu and H. Li, "Interval-Valued Intuitionistic Fuzzy Power Bonferroni Aggregation Operators and Their Application to Group Decision Making," Cognitive Computation, pp. 1-19, 2017.

[35] R. Lahdelma and P. Salminen, "SMAA-2: stochastic multicriteria acceptability analysis for group decision making," Operations Research, vol. 49, no. 3, pp. 444-454, 2001.

[36] P. Liu, S.-M. Chen, and J. Liu, "Multiple attribute group decision making based on intuitionistic fuzzy interaction partitioned Bonferroni mean operators," Information Sciences, vol. 411, pp. 98-121, 2017.

[37] M. Grabisch, C. Labreuche, and J.-C. Vansnick, "On the extension of pseudo-Boolean functions for the aggregation of interacting criteria," European Journal of Operational Research, vol. 148, no. 1, pp. 28-47, 2003.

[38] M. Grabisch, S. Greco, and M. Pirlot, "Bipolar and bivariate models in multicriteria decision analysis: Descriptive and constructive approaches," International Journal of Intelligent Systems, vol. 23, no. 9, pp. 930-969, 2008.

[39] A. M. M. Sharif Ullah and J. Tamaki, "Analysis of Kano-modelbased customer needs for product development," Systems Engineering, vol. 14, no. 2, pp. 154-172, 2011.

[40] P. Ji, J. Jin, T. Wang, and Y. Chen, "Quantification and integration of Kano's model into QFD for optimising product design," International Journal of Production Research, vol. 52, no. 21, pp. 6335-6348, 2014.

[41] J. Lin, J.-B. Lan, and Y.-H. Lin, "A method of multi-attribute group decision-making based on the aggregation operators for interval two-tuple linguistic information," Jilin Normal University Journal(Natural Science Edition), vol. 1, pp. 5-9, 2009.

[42] Y. C. Dong, Y. F. Xu, H. Y. Li, and B. Feng, "The OWA-based consensus operator under linguistic representation models using position indexes," European Journal of Operational Research, vol. 203, no. 2, pp. 455-463, 2010.

[43] G. Wei, "A method for multiple attribute group decision making based on the ET-WG and ET-OWG operators with 2-tuple linguistic information," Expert Systems with Applications, vol.37, no. 12, pp. 7895-7900, 2010.

[44] H. Zhang, "The multiattribute group decision making method based on aggregation operators with interval-valued 2-tuple linguistic information," Mathematical and Computer Modelling, vol. 56, no. 1-2, pp. 27-35, 2012. 
[45] H. Zhang, "Some interval-valued 2-tuple linguistic aggregation operators and application in multiattribute group decision making," Applied Mathematical Modelling: Simulation and Computation for Engineering and Environmental Systems, vol. 37, no. 6, pp. 4269-4282, 2013.

[46] S. R. Gangurde and M. M. Akarte, "Customer preference oriented product design using AHP-modified TOPSIS approach," Benchmarking, vol. 20, no. 4, pp. 549-564, 2013.

[47] P. Liu and S.-M. Chen, "Multiattribute group decision making based on intuitionistic 2-tuple linguistic information," Information Sciences, vol. 430/431, pp. 599-619, 2018.

[48] J. D. Qin, X. W. Liu, and W. Pedrycz, "An extended VIKOR method based on prospect theory for multiple attribute decision making under interval type-2 fuzzy environment," KnowledgeBased Systems, vol. 86, pp. 116-130, 2015.

[49] Y. M. Wang, Y. Luo, and Z. Hua, "On the extent analysis method for fuzzy AHP and its applications," European Journal of Operational Research, vol. 186, no. 2, pp. 735-747, 2008. 


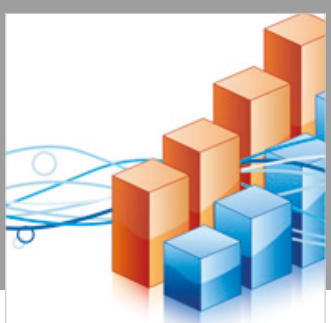

Advances in

Operations Research

\section{-n-m}
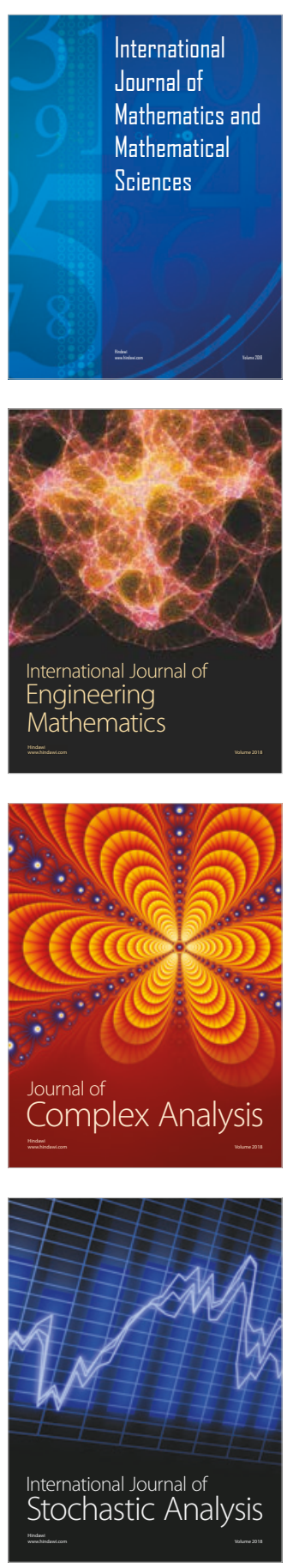
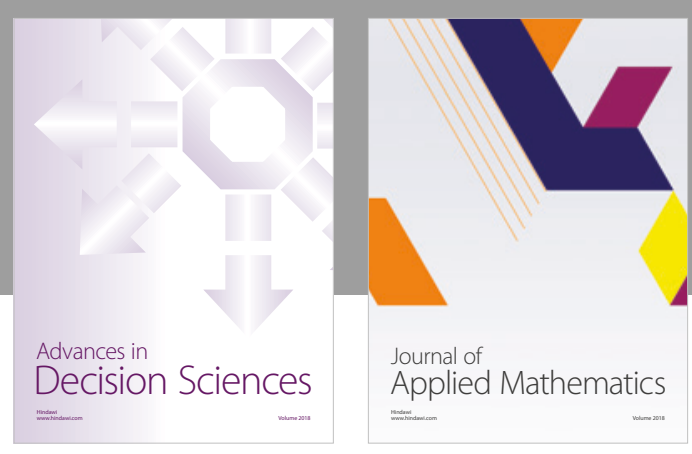

Journal of

Applied Mathematics
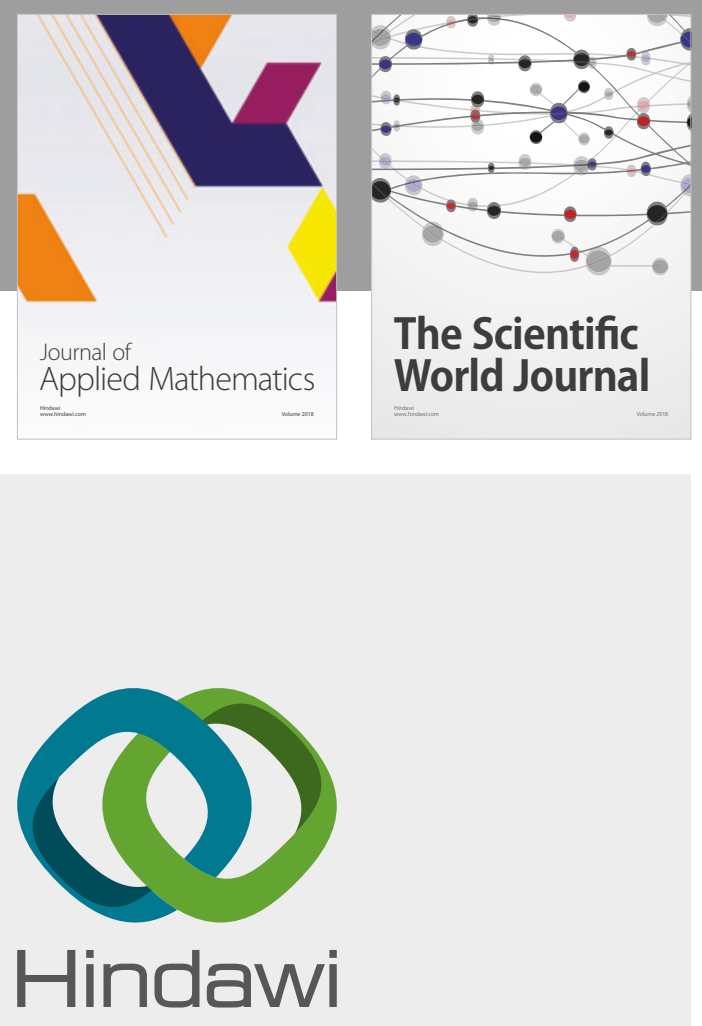

Submit your manuscripts at

www.hindawi.com

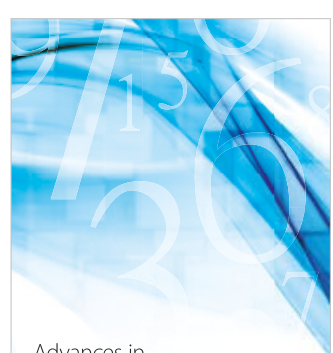

Advances in
Numerical Analysis
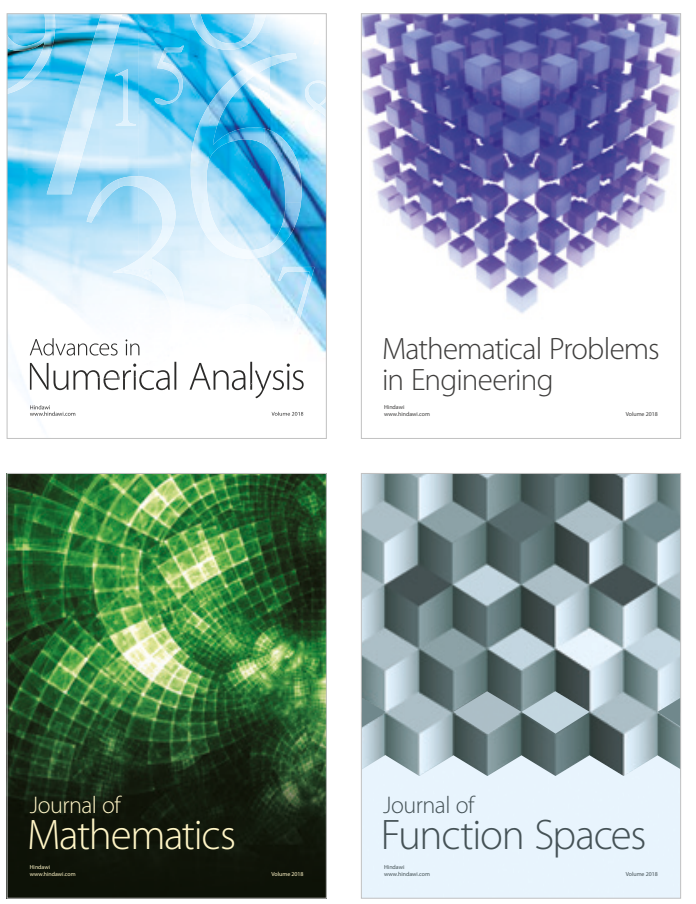

Mathematical Problems in Engineering

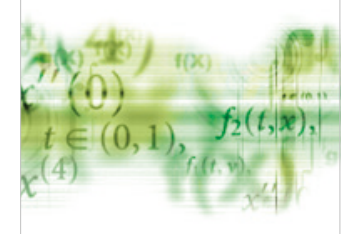

International Journal of

Differential Equations

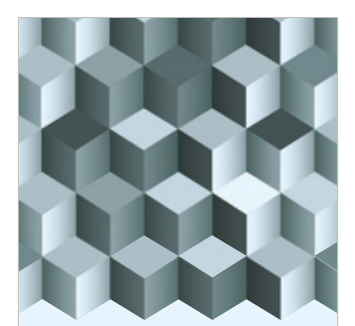

Journal of

Function Spaces

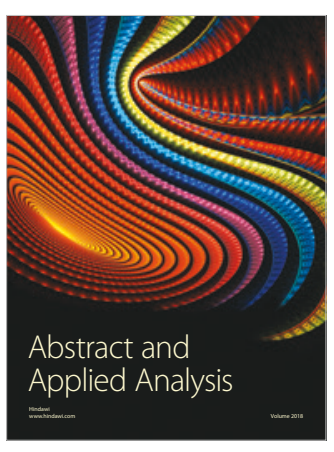

The Scientific

World Journal

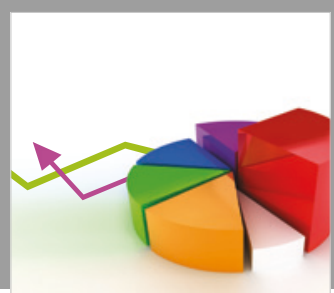

Journal of

Probability and Statistics
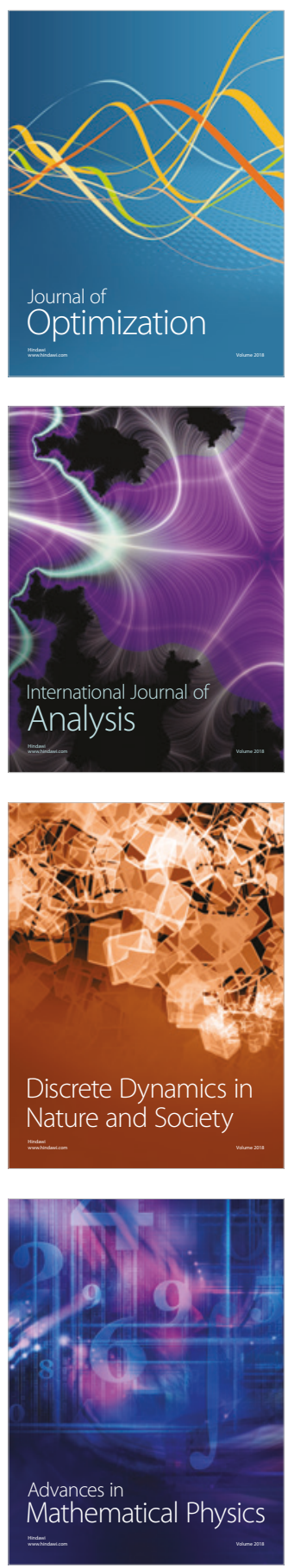